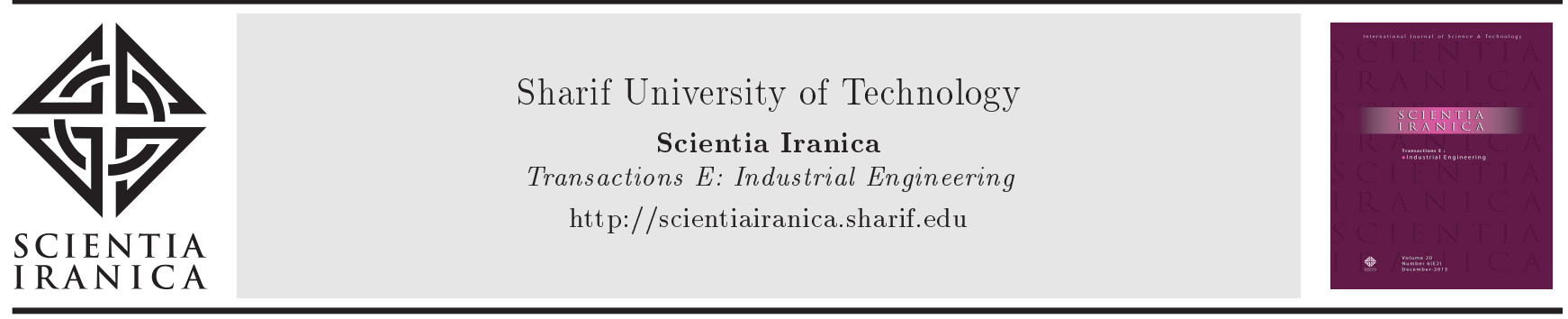

\title{
Stackelberg models in a two-level supply chain with imperfect quality items and allowable shortage
}

\author{
R. Yadav ${ }^{\mathrm{a}}$, S. Pareek ${ }^{\mathrm{a}}$, and M. Mittal ${ }^{\mathrm{b}, *}$ \\ a. Apaji Institute of Mathematics and Applied Computer Technology, Banasthali University, Rajasthan, 304022, India. \\ b. Department of Computer Science Engineering, Amity School of Engineering and Technology, Bijwasan, New Delhi, India.
}

Received 2 March 2019; received in revised form 8 December 2020; accepted 18 January 2021

\author{
KEYWORDS \\ Game theory; \\ Imperfect quality \\ items; \\ Non-cooperative \\ games; \\ Shortages; \\ Supply chain.
}

\begin{abstract}
Given that the application of an absolute supply chain model does not invalidate the possibility of few defective items in a supplied lot, it is essential to conduct an inspection to segregate defective items so as to sell such segregated items at a discount. Shortage mainly occurs with sudden rise of demand or erratic production capacity affecting a player's decisions. In this paper, shortage is considered as the seller's decision variable, and demand is receptive to the selling price and marketing expenditure of the buyer. The interaction of players will in turn be reviewed and determined as a non-cooperative Stackelberg game. Further, a supply chain model is proposed to substantiate the interaction between buyer and seller in the supply chain, and it is pitched by non-cooperative game theoretical approaches. The Stackelberg game approach is used as an extension of the non-cooperative method according to which one player acts as the leader and the other as a follower. Hereafter, unanimous numerical examples along with sensitivity analysis will be given to compare the two different models in the absence and presence of shortages to highlight the significance of this study.
\end{abstract}

(C) 2023 Sharif University of Technology. All rights reserved.

\section{Introduction}

In the last few decades, many researchers and academicians have assessed and magnified the supply chain system and then, optimized such methods as sellerbuyer coordination, business process management, and information sharing [1]. The seller-buyer supply chain represents the relationship between the two players (seller and buyer); the seller vends goods to the buyer in a lot while the latter sells them to the customer [2-

*. Corresponding author. Tel./Fax: +91-989-140-2516 E-mail addresses: ritayadav76@gmail.com (R. Yadav); psarla@gmail.com (S. Pareek); mittal_mandeep@yahoo.com (M. Mittal)

doi: $10.24200 /$ sci.2021.51648.2292
4]. Several concepts such as credit option, quantity discount, buy back, and quantity flexibility have been discussed with respect to supply chain management in the last few years. Chiang et al. [5], Sarmah et al. [6], Weng [7], and Shekarian [8] reviewed the factors affecting the closed-loop supply chain models. With the assumption of demand as a fixed constant, researchers like Chan and Kingsman [9], Dai and Qi [10], Van den Heuvel et al. [11], and Sucky [12,13] contributed to the knowledge on supply chain management by determining the ideal lot size and order cycle to optimize the profitability of the supply chain. Gautam and Khanna [14] presented a sustainable framework under a two-level supply chain environment. The seller runs the manufacturing process to assist the marketing demand of the buyer. Researchers like Lee [15], Abad [16], Kim and Lee [17], and Jung and 
Klein [18] developed a supply chain model in which the end demand fluctuated with respect to the buyer's price to obtain the optimal policy for both parties. Abad and Jaggi [19] further improved the model proposed by Abad [16] by allowing the seller to give a credit period to the buyer such that sellers and buyers optimize their strategy under cooperative and non-cooperative game theory structures. Sadjadi et al. [20] and Lee and Kim [21] proposed models to determine the optimal policies in which the demand was a function of the selling price and marketing expenditure. Esmaeili et al. [22] employed the demand function to design models of non-cooperative and cooperative game approaches following symmetric information pattern; in other words, both players work unanimously. Esmaeili and Zeephongsekul [23] proposed a similar model under asymmetric information structure, i.e., both players work ambiguously. Silbermayr [24] discussed the news-vendor problem using a non-cooperative game approach in the inventory management by describing a single period inventory control model with the main focus on the horizontal interactions among multiple independent newsvendors.

The aforementioned studies assumed that all the items were of perfect quality despite common manufacturing of defective items in quality during the production process. These items are then identified in an inspection process at the buyer's end. The inventory models of defective items were investigated by Schwaller [25] and Rosenblatt and Lee [26]; then, they were extended by Salameh and Jaber [27] by allowing defective quality items to be sold at discounted prices post inspection. Maddah and Jaber [28] used renewal-reward theorem Ross [29] to determine the total expected profit per unit time. None of the refereed papers did not take into account the possibility of shortages occurring at any point in the production cycle due to either irregular production or an increase in demand. The buyer may be forced to order large quantities of goods out of the fear of shortages, which ultimately increases the holding cost. Essentially, shortage size needs to be optimized. In this regard, Wee et al. [30] made contributions to the model proposed by Salameh and Jaber [27] by placing repeated order of shortfalls in each cycle. Eroglu and Ozdemir [31] incorporated the concept of backordering at times of shortage and reviewed the results of defective quality items in the case of lot size and optimal profit. Consequently, numerous related papers for controlling imperfect quality items have been published by Sarkar [32], Sarkar and Moon [33], Roy et al [34], Cheikhrouhou et al. [35], and Sarkar et al. [36] who reexamined the EPQ model as a singlestage manufacturing system with rework process and planed backorders, allowing random defective rates. Three inventory models were then developed, and a comparison was made between the modes with three different probability density functions. An inventory model for non-instantaneous deteriorating items was proposed by Tiwari et al. [37] and they incorporated acceptable delay in payments and improved an optimal policy with respect to shortages. Jaggi et al. [38] proposed an inventory model with justifiable delays in payments for items of defective quality while shortages were allowed. Khanna et al. [39] proposed an inventory model with delay in payments for deteriorating imperfect quality items where shortages were allowed and completely backlogged.

Khanna et al. [40] developed an integrated vendor-buyer inventory model for imperfect quality items with allowable shortages under the permissible delay in payments. Kishore et al. [41] studied and optimized the production and backordering quantities in order to maximize the total expected profit per unit time. Khanna et al. [42] jointly optimized the number of shipments, backorder size, and order size in order to minimize the integrated total cost of the seller and the buyer. Jaggi et al. [43] considered a two-warehouse inventory model for imperfect-quality deteriorating items with one level of credit period. The presented inventory model maximized the total profit per unit time by optimizing the ordered quantity. Mittal et al. [44] discussed the effect of inspection on the ordering policy of the retailer in a permissible delay in payments for defective deteriorating items, where both price and demand quantities vary with time.

Esmaeili [45] presented a new approach to find the lot size by a non-cooperative game-theoretic approach (Seller-Stackelberg and Buyer-Stackelberg). Yadav et al. [46] presented supply chain models with imperfectquality items with allowable late payments under cooperative and non-cooperative (Seller-Stackelberg) analogues where the market demand of the product depended upon the retail price. The optimal policies of the partners in the supply chain were obtained in each scenario, which would enhance the profitability of the supply chain. Sarkar et al. [47] developed an integrated inventory model that optimized the joint cost of a vendor and a buyer through the Stackelberg game approach. The buyer used the inspection policy to identify the defective items. Based on the fixed number of shipments, variable transportation with carbon emissions was considered in the model, making the model more sustainable. Lu et al. [48] obtained the optimal equilibrium solution between the buyer and the seller using the Stackelberg game-theoretic approach under different carbon emission reductions.

Alaei and Setak [49] discussed an optimization problem in an advertising environment under noncooperative (Stackelberg) and cooperative game approaches in a supply chain system. The coordination between the partners in the supply chain has been 
discussed through a two-way subsidy strategy under two scenarios (exogenously and endogenously). Jaggi et al. [50] considered a supplier-retailer supply chain in which the demand was stock dependent with credit period. The proposed model could find the optimal decisions of the supply chain under three different policies, namely the centralized, Nash equilibrium solution, and Supplier-Stackelberg policy. Yadav et al. [51] developed a supply chain model to substantiate the interaction and concurrence between the members of the supply chain, i.e., the buyer and seller, which was established by non-cooperative and cooperative gametheoretic approaches where the end demand depends upon the retailer price and marketing expenditure cost. Gautam et al. [52] developed two types of models: The first model discussed the integrated problem-solving approach and the second model used the Stackelberg policy. The total profit is maximized by jointly optimizing the number of shipments, order quantity, and backordering quantity.

Zhang et al. [53] developed a supply chain model based on game-theoretic cooperative and noncooperative approaches in which the decision variable of the seller was considered shortage and demand depended on the selling price and marketing promotional cost of the buyer. Zhang and Zeephongsekul [54] expanded the work of Zhang et al. [53] with the same constraints and developed two mechanism design agreement provided to the buyer by the seller as an incentive to increase the player's profit.

Game theory is the advanced study of mathematical models of dispute and cooperation between the players or decision makers. Non-cooperative game theory approaches were designed to examine the interaction between the participants and problems within a supply chain. No researcher has developed any supply chain models incorporating the imperfect quality items by taking shortages as a decision variable based on the game theoretic approach. In this model, the sellerbuyer model with imperfect quality items, where shortages were also allowed, was developed based on the concept of non-cooperative game. In the present model, the seller delivers items in a lot to the buyer, who then segregates items of degraded quality through an inspection process. These items of sub-par quality are then sold at a discount. The seller's rate of production is assumed to be linearly dependent on rate of demand. Both selling price and marketing expenditure of the leading player are considered to determine the end demand, as players with more influence often gain higher profit than others in a market.

The main contribution of the paper includes the following points:

- The buyer considers the ordering quantity as his decision variable. In the small/medium entrepreneur- ship, based on the market demand, the buyer always raises the requirement for the seller;

- Shortages occur due to uneven production capacity or unpredictable demands, thus affecting both players' decisions. The seller regulates it to reduce its effect on the supply chain system. Due to shortages, the buyer may be forced to order large quantities to offset the profit loss, hence increased holding cost. In case the buyer faces large shortage, he might be inclined towards alternative sources of supply and as a result, the seller's profit will be affected, as well. Therefore, optimization of the shortage size is of high importance for both the players;

- The order quantity, buyer price, and marketing expenditure are taken as the decision variable of the buyer, whereas shortages and seller price are the decision variables of the seller. Here, two scenarios can be taken into consideration: a) the seller acts as the leader (Seller-Stackelberg) and b) buyer acts as the leader (Buyer-Stackelberg).

Authors' contribution is given in Table 1.

\section{Notations and assumptions}

\subsection{Notations}

Decision variables of the seller:

$c_{b} \quad$ Buyer's purchasing cost ( $\$$ per unit)

$S \quad$ Shortages managed by the seller (units)

Decision variables of the buyer:

$Q \quad$ Order quantity (units)

$M \quad$ Cost of marketing expenses $(\$$ per unit)

$p_{b} \quad$ Buyer's retail price (\$ per unit)

Parameters:

$C \quad$ Seller's purchasing cost ( $\$$ per unit)

$A_{b} \quad$ Buyer's ordering cost ( $\$$ per order)

$A_{s} \quad$ Seller's ordering cost ( $\$$ per order)

$I \quad$ Percent inventory carrying cost $(\$$ per unit)

$H_{b} \quad$ Carrying cost of inventory (\$ per unit per time)

$\alpha \quad$ Proportion of sub-par quality items delivered to buyer by the seller

$T_{1} \quad$ Buyer's cycle length (years), $T_{1}=Q(1-\alpha) / D$

$T_{2} \quad$ Seller's cycle length (years), $T_{2}=Q / D$

$T \quad$ Length of cycle in Stackelberg model (years), $T=\max \left(T_{1}, T_{2}\right)$ 
Table 1. Contribution of several authors to the associated field.

\begin{tabular}{|c|c|c|c|c|}
\hline Author(s) & $\begin{array}{c}\text { Supply chain } \\
\text { model }\end{array}$ & Inspection & $\begin{array}{c}\text { Non-cooperative game } \\
\text { without shortages }\end{array}$ & $\begin{array}{c}\text { Non-operative games } \\
\text { with shortages }\end{array}$ \\
\hline Schwaller [25] & $\checkmark$ & $\checkmark$ & & \\
\hline Lee $[15]$ & $\checkmark$ & & & \\
\hline Lee and Kim [21] & $\checkmark$ & & & \\
\hline Chiang et al. [5] & $\checkmark$ & & & \\
\hline Abad $[16]$ & $\checkmark$ & & & \\
\hline Kim and Lee ([17] & $\checkmark$ & & & \\
\hline Salameh and Jaber [27] & $\checkmark$ & $\checkmark$ & & \\
\hline Abad and Jaggi [19] & $\checkmark$ & & $\checkmark$ & \\
\hline Sadjadi et al. [20] & $\checkmark$ & & & \\
\hline Jung and Klein [18] & $\checkmark$ & & & \\
\hline Sucky $[12,13]$ & $\checkmark$ & & & \\
\hline Sarmah et al. [6] & $\checkmark$ & & & \\
\hline Eroglu and Ozdemir [31] & $\checkmark$ & $\checkmark$ & & \\
\hline Dai and Qi [10] & $\checkmark$ & & & \\
\hline Van den Heuvel et al. [11] & $\checkmark$ & & & \\
\hline Chan and Kingsman [9] & $\checkmark$ & & & \\
\hline Esmaeili et al. [22] & $\checkmark$ & & $\checkmark$ & \\
\hline Esmaeili and Zeephongsekul [23] & $\checkmark$ & & $\checkmark$ & \\
\hline Roy et al. [34] & $\checkmark$ & $\checkmark$ & & \\
\hline Sarkar and Moon [33] & $\checkmark$ & $\checkmark$ & & \\
\hline Zhang et al. [53] & $\checkmark$ & & $\checkmark$ & $\checkmark$ \\
\hline Sarkar [32] & $\checkmark$ & $\checkmark$ & & \\
\hline Jaggi et al. [38] & $\checkmark$ & $\checkmark$ & & \\
\hline Sarkar et al. [36] & $\checkmark$ & $\checkmark$ & & \\
\hline Tiwari et al. [37] & $\checkmark$ & & & \\
\hline Khanna et al. [40] & $\checkmark$ & $\checkmark$ & & \\
\hline Alaei and Setak [49] & $\checkmark$ & & $\checkmark$ & \\
\hline Sarkar et al. $[47]$ & $\checkmark$ & $\checkmark$ & $\checkmark$ & \\
\hline Esmaeili [45] & $\checkmark$ & & $\checkmark$ & \\
\hline Zhang and Zeephongskul [54] & $\checkmark$ & & $\checkmark$ & $\checkmark$ \\
\hline Mittal et al. [44] & $\checkmark$ & $\checkmark$ & & \\
\hline Jaggi et al. [43] & $\checkmark$ & $\checkmark$ & & \\
\hline Yadav et al. [46] & $\checkmark$ & $\checkmark$ & $\checkmark$ & \\
\hline Yadav et al. [51] & $\checkmark$ & $\checkmark$ & $\checkmark$ & \\
\hline Cheikhrouhou et al. [35] & $\checkmark$ & $\checkmark$ & & \\
\hline Jaggi et al. [50] & $\checkmark$ & & $\checkmark$ & \\
\hline Kishore et al. [41] & $\checkmark$ & & & \\
\hline Gautam et al. [52] & $\checkmark$ & & $\checkmark$ & \\
\hline Lu et al. [48] & $\checkmark$ & & $\checkmark$ & \\
\hline Silbermayr [24] & $\checkmark$ & & $\checkmark$ & \\
\hline Present paper & $\checkmark$ & $\checkmark$ & $\checkmark$ & $\checkmark$ \\
\hline
\end{tabular}


$c_{s}$

Cost of imperfect quality items $(\$$ per unit) $\left(c_{s}<c_{b}\right)$

$\lambda \quad$ Buyer's rate of screening (unit per year)

$t \quad$ Screening time to find the defective items, $t=Q / \lambda$ (years)

$C_{1} \quad$ Buyer's shortages cost ( $\$$ per unit)

$C_{2} \quad$ Seller's shortages cost ( $\$$ per unit)

$k \quad$ Scaling constant for Marketing demand $(k>0)$

$r \quad$ Seller's rate of production (unit per cycle)

$u \quad$ Scaling constant for production $(u>1)$

$d \quad$ Demand rate (unit per cycle)

$e \quad$ Price elasticity for marketing demand $(e>1)$

$\beta \quad$ Marketing expenditure elasticity for marketing demand $(0<\beta<1$, $\beta+1<e)$

$D \quad$ Annual market demand, i.e., a function of selling price $p_{b}$ and marketing expenditure $M$, such that $D=k p_{b}^{-e} M^{\beta}[22]$.

\subsection{Assumptions}

1. The annual market demand is a multiplicative power function of the selling price, $p_{b}$, and marketing expenditure, $M$, of the buyer;

2. Infinite planning horizon;

3. Parameters are known in advance and deterministic under symmetric information scenario;

4. The buyer determines the lot size;

5. It is assumed that defective items are distributed uniformly in each lot [38];

6. Shortage occurs due to unanticipated demand or irregular production capacity by the seller so as to reduce the effect on the supply chain system;

7. The production rate is greater than the demand rate. It is assumed that the demand rate and production rate are linearly related as $r=u d$, $u>1$, where $r$ and $d$ stand for the production and demand rates, respectively [53].

\section{Mathematical formulation}

This section presents the mathematical description of non-cooperative models for both buyer (BuyerStackelberg) and seller (Seller-Stackelberg) to optimize the expected profits of the supply chain. The supply chain problem is considered to be a two-player nonzero-sum game.

\subsection{Buyer's model}

The buyer's objective is to determine his decision variables namely $p_{b}, M$, and $Q$ so as to maximize the total expected profit. The buyer's total annual profit, $T P_{b}\left(p_{b}, M\right)$, is given by:

$T P_{b}\left(p_{b}, M, Q\right)=$ Sales revenue - Purchasing cost

- Ordering cost - Marketing cost - Holding cost

- Shortages cost.

The holding cost is expressed in terms of the percentage of positive inventory $I c_{b} A$ and shortages cost in terms of percentage of the negative inventory $C_{1} B$. The values of the constants $A$ and $B$ can be found with inventory fluctuation diagram in Figure 1 [55].

The player has both positive and negative inventories in the inventory process. Positive inventory is given by positive area at times $t_{1}$ and $t_{4}$. Negative inventory is given by the negative area at times $t_{2}$ and $t_{3}$. The average positive and negative inventories can be measured as shown below:

$$
\begin{aligned}
& T_{p}=t_{3}+t_{4}=Q / r, \\
& I_{m}=T_{p}(r-d)-S=Q\left(1-u^{-1}\right)-S,
\end{aligned}
$$

where:

$$
\begin{array}{ll}
u=r / d, \quad t_{1}=\frac{(1-\alpha) I_{m}}{d}, \quad t_{2}=\frac{S}{d}, \\
t_{3}=\frac{S}{r-d}, \quad \text { and } \quad t_{4}=\frac{I_{m}}{r-d} .
\end{array}
$$

Thus, the positive inventory area is:

$$
\begin{aligned}
A & =\frac{1}{2}(1-\alpha) t_{1} I_{m}+(\alpha Q) Q t+\frac{1}{2} t_{4} I_{m} \\
& =\frac{1}{2} d(1-\alpha)^{2} I_{m}{ }^{2}+\frac{\alpha Q^{2}}{\lambda}+\frac{1}{2(r-d)} I_{m}{ }^{2} .
\end{aligned}
$$

The negative inventory area is:

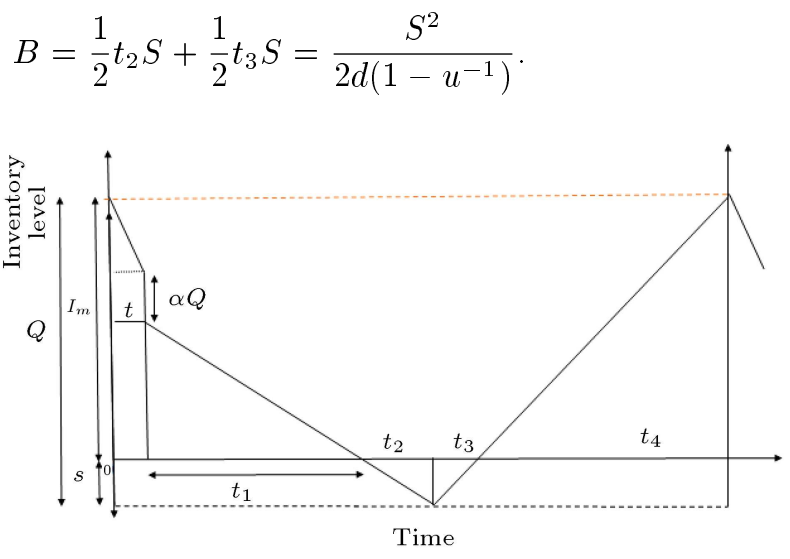

Figure 1. Inventory fluctuation diagram with imperfect quality items. 
Put $t=\frac{Q}{\lambda}, H_{b}=I c_{b}$; then, the buyer's profit becomes:

$$
\begin{gathered}
T P_{b}\left(p_{b}, M, Q\right)=p_{b}(1-\alpha) Q+c_{s} \alpha Q-c_{b} Q-M Q \\
-A_{b}-A I c_{b}-C_{1} B=p_{b}(1-\alpha) Q+c_{s} \alpha Q-c_{b} Q \\
-M Q-A_{b}-\left(\frac{1}{2 d}(1-\alpha)^{2} I_{m}^{2}+\frac{\alpha Q^{2}}{\lambda}\right. \\
\left.+\frac{1}{2(r-d)} I_{m}{ }^{2}\right) I c_{b}-C_{1} \frac{S^{2}}{2 d\left(1-u^{-1}\right)} .
\end{gathered}
$$

Let the cycle length be $T_{1}=\frac{1-\alpha) Q}{D}$.

Therefore, the expected value of the buyer's total profit is given by:

$$
\begin{aligned}
& E\left[T P_{b}\left(p_{b}, M, Q\right)\right]=\left[p_{b}(1-E[\alpha]) Q+c_{s} E[\alpha] Q\right. \\
& -c_{b} Q-M Q-A_{b}-\left(\frac{I_{m}^{2} E\left[(1-\alpha)^{2}\right]}{2 d}+\frac{E[\alpha] Q^{2}}{\lambda}\right. \\
& \left.\left.+\frac{1}{2(r-d)} I_{m}^{2}\right) I c_{b}-C_{1} \frac{S^{2}}{2 d\left(1-u^{-1}\right.}\right] .
\end{aligned}
$$

Renewal theory proposed by Maddah and Jaber [28] was employed to determine the expected value of the buyer's total profit per cycle. Then, we have:

$$
\begin{aligned}
& E\left[T P_{b}^{c}\left(p_{b}, M, Q\right)\right]=E\left[\frac{T P_{b}\left(p_{b}, M, Q,\right)}{T_{1}}\right] \\
& \frac{E\left[T P_{b}\left(p_{b}, M, Q\right)\right]}{E\left[T_{1}\right]}=\frac{D}{Q(1-E[\alpha])}\left[p_{b}(1-E[\alpha]) Q\right. \\
& +c_{s} E[\alpha] Q-c_{b} Q-M Q-A_{b}-\left(\frac{I_{m}{ }^{2} E\left[(1-\alpha)^{2}\right]}{2 D}\right. \\
& \left.\left.+\frac{E[\alpha] Q^{2}}{\lambda}+\frac{1}{2(r-D)} I_{m}^{2}\right) I c_{b}-C_{1} \frac{S^{2}}{2 D\left(1-u^{-1}\right)}\right] .
\end{aligned}
$$

Demand function is assumed to be $k p_{b}^{-e} M^{\beta}$; then, we have:

$$
\begin{gathered}
\frac{E\left[T P_{b}\left(p_{b}, M, Q\right)\right]}{E\left[T_{1}\right]}=\frac{k p_{b}^{-e} M^{\beta}}{Q(1-E[\alpha])}\left[p_{b}(1-E[\alpha]) Q\right. \\
+c_{s} E[\alpha] Q-c_{b} Q-M Q-A_{b}-\left(\frac{I_{m}{ }^{2} E\left[(1-\alpha)^{2}\right]}{2 D}\right. \\
\left.\left.+\frac{\left.E[\alpha] Q^{2}\right)}{\lambda}+\frac{1}{2(r-D)} I_{m}^{2}\right) I c_{b}-C_{1} \frac{S^{2}}{2 D\left(1-u^{-1}\right)}\right]
\end{gathered}
$$

In order to maximize the expected profit, $E\left[T P_{b}^{c}\left(p_{b}\right.\right.$, $M, Q)$ ] of the buyer, we must find the optimal values of his decision variables, namely $p_{b}, M$, and $Q$. To determine the optimal value of $p_{b}$, Eq. (1) should be differentiated with respect to $p_{b}$ for constant $M$ and $Q$ and equated to zero:

$$
\frac{\partial E\left[T P_{b}^{c}\left(p_{b}, M, Q\right)\right]}{\partial p_{b}}=0
$$

which yields:

$$
\begin{aligned}
p_{b}= & \frac{e}{(e-1)(1-E[\alpha])}\left[M+c_{b}+\frac{A_{b}}{Q}\right. \\
& \left.+\frac{\left.I c_{b} E[\alpha] Q\right)}{\lambda}-c_{s} E[\alpha]\right] .
\end{aligned}
$$

As seen in Appendix A, the pseudo concavity of the expected profit function with respect to $p_{b}$ for fixed $M$ and $Q$ is proved.

Upon substituting Eq. (2) into Eq. (1), we get:

$$
\begin{gathered}
E\left[T P_{b}^{c}\left(p_{b}(M), M, Q(M)\right)\right]=\frac{K}{e}\left[\frac{e}{(e-1)(1-E[\alpha])}\right. \\
\quad\left[M+c_{b}+\frac{A_{b}}{Q}+\frac{I c_{b} E[\alpha] Q}{\lambda}-c_{s} E[\alpha]\right]^{-e+1} M^{\beta} \\
-\frac{1}{2 Q(1-E[\alpha])}\left(\left(E\left[(1-\alpha)^{2}\right]+(u-1)^{-1}\right) I c_{b}\right. \\
\quad\left(Q\left(1-u^{-1}-S\right)^{2}\right)-C_{1} \frac{S^{2}}{2\left(1-u^{-1}\right)(1-E[\alpha])}
\end{gathered}
$$

Similarly, to determine the optimal value of $M$, by differentiating Eq. (1) is once with respect to $M$ and equating it to zero, we have:

$$
\frac{\partial E\left[T P_{b}^{c}\left(p_{b}(M), M, Q(M)\right)\right]}{\partial M}=0,
$$

which gives the value of $M$ :

$$
M=\frac{\beta}{(e-\beta-1)}\left[c_{b}+\frac{A_{b}}{Q}+\frac{\left.I c_{b} E[\alpha] Q\right)}{\lambda}-c_{s} E[\alpha]\right] \text {. }
$$

As seen in Appendix B, the concavity of the given expected profit function of the buyer with respect to $M$ is proved. Substituting Eq. (4) into Eq. (2) will yield:

$$
\begin{aligned}
p_{b}= & \frac{e}{(e-\beta-1)(1-E[\alpha])}\left[c_{b}+\frac{A_{b}}{Q}+\frac{\left.I c_{b} E[\alpha] Q\right)}{\lambda}\right. \\
& \left.-c_{s} E[\alpha]\right] .
\end{aligned}
$$

By substituting the values of Eqs. (4) and (5) in Eq. (1), 


$$
\begin{aligned}
& E\left[T P_{b}^{c}(Q)\right]=k \frac{e}{(e-\beta-1)(1-E[\alpha])}\left(c_{b}+\frac{A_{b}}{Q}+\frac{I c_{b} E[\alpha] Q}{\lambda}-c_{s} E[\alpha]\right)^{-e+1} \frac{\beta}{(e-\beta-1)} \\
& \quad\left(c_{b}+\frac{A_{b}}{Q}+\frac{I c_{b} E[\alpha] Q}{\lambda}-c_{s} E[\alpha]\right)^{\beta} \\
& +\frac{K \frac{e}{(e-\beta-1)(1-E[\alpha])}\left(c_{b}+\frac{A_{b}}{Q}+\frac{I c_{b} E[\alpha] Q}{\lambda}-c_{s} E[\alpha]\right)^{-e}\left(\frac{\beta}{(e-\beta-1)}\left(c_{b}+\frac{A_{b}}{Q}+\frac{I c_{b} E[\alpha] Q}{\lambda}-c_{s} E[\alpha]\right)^{\beta}\right)}{(1-E[\alpha])} \\
& \quad\left[c_{s} E[\alpha]-c_{b}-M-\frac{A_{b}}{Q}-\frac{E[\alpha] Q}{\lambda} I c_{b}\right]-\frac{1}{2 Q(1-E[\alpha])}\left(\left(E\left[(1-\alpha)^{2}\right]+(u-1)^{-1}\right) I c_{b}\left(Q\left(1-u^{-1}-S\right)^{2}\right)\right. \\
& -C_{1} \frac{S^{2}}{2\left(1-u^{-1}\right)(1-E[\alpha])}
\end{aligned}
$$

Box I

we have Eq. (6) shown in Box I. The first-order conditions of Eq. (6) with respect to $Q$ are as follows:

$$
\begin{gathered}
2 D\left(A_{b}-E[\alpha] I C_{b} \lambda^{-1} Q^{2}\right)=\left(\left(1-u^{-1}\right)^{2} Q^{2}-S^{2}\right) \\
\frac{I c_{b}\left(E\left[(1-\alpha)^{2}\right]+(u-1)^{-1}\right)}{(1-E[\alpha])} \\
-\left(\frac{C_{1} S^{2}}{\left(1-u^{-1}\right)(1-E[\alpha])}\right)
\end{gathered}
$$

i.e.:

$$
\begin{aligned}
2 k e^{-e} \beta^{\beta} & \left(c_{b}+\frac{A_{b}}{Q}+\frac{I c_{b} E[\alpha] Q}{\lambda}-c_{s} E[\alpha]\right)^{\beta-e} \\
& (e-\beta-1)^{e-\beta}(1-E[\alpha])^{e}\left(A_{b}-E[\alpha] I C_{b} \lambda^{-1} Q^{2}\right) \\
= & \left(\left(1-u^{-1}\right)^{2} Q^{2}-S^{2}\right) \frac{I C_{b}\left(E\left[(1-\alpha)^{2}\right]+(u-1)^{-1}\right)}{(1-E[\alpha])} \\
& -\left(\frac{C_{1} S^{2}}{\left(1-u^{-1}\right)(1-E[\alpha])}\right) .
\end{aligned}
$$

It is quite difficult to analytically prove the concavity of Eq. (6) with respect to $Q$; thus, the expected total profit $E\left[T P^{c}\left(p_{b}(Q), M(Q), Q\right)\right]$ defined in Eq. (6) is the concave function with respect to $Q$ which is shown with the help using the graph (Figure 2).

\subsection{Seller's model}

To maximize the seller's net profit, we should determine the optimal value of the selling price, $c_{b}$. The profit function of the seller is expressed as:

$T P_{s}\left(c_{b}, Q\right)=$ Sales Revenue - Production cost

- Set up cost - Holding cost - Shortages cost.

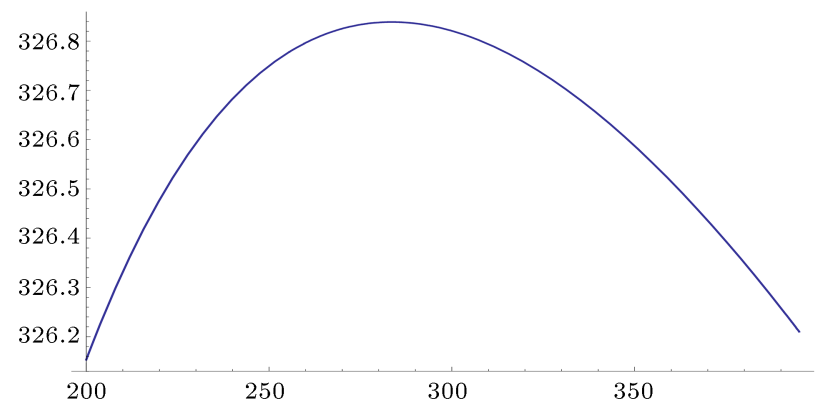

Figure 2. Buyer's expected total profit with respect to $Q$.

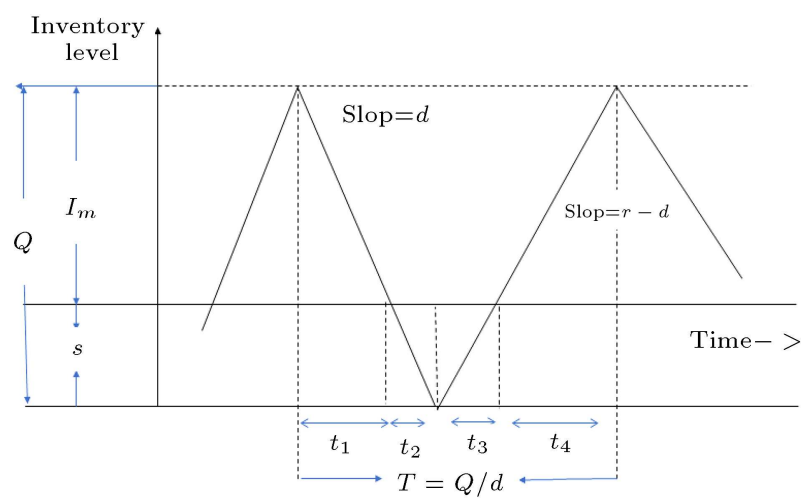

Figure 3. Inventory fluctuation diagram.

Figure 3 is a general inventory fluctuation diagram given by Johnson and Montgomery [55]. This figure helps find the positive and negative inventories for the seller in the time span of the inventory process.

According to Figure 3, the positive areas in the time spans $t_{1}$ and $t_{4}$ show the positive inventory. The negative areas in $t_{2}$ and $t_{3}$, on the contrary, represent the negative inventory. Both positive and negative inventories are calculated as follows [53]: 
Positive inventory $=\frac{1}{2} t_{1} I_{m}+\frac{1}{2} t_{4} I_{m}$

$$
=\frac{\left(Q\left(1-u^{-1}\right)-S\right)^{2}}{2 d\left(1-u^{-1}\right)},
$$

Negative inventory $=\frac{1}{2} t_{2} S+\frac{1}{2} t_{3} S$

$$
=\frac{S^{2}}{2 d\left(1-u^{-1}\right)},
$$

$T_{2}$ (cycle length for the seller) $=\frac{Q}{d}$.

The profit of the seller per cycle is:

$$
\begin{aligned}
T P_{s}^{c}\left(c_{b}, S\right)=\left(c_{b} D-C D-\frac{A_{s}}{Q} D\right) \\
\quad-\frac{\left(Q\left(1-u^{-1}\right)-S\right)^{2}}{2 Q\left(1-u^{-1}\right)} I C-\frac{S^{2}}{2 Q\left(1-u^{-1}\right)} C_{2} \\
=K p_{b}^{-e} M^{\beta}\left(c_{b}-C-\frac{A_{S}}{Q}\right) \\
\quad-\frac{\left(Q\left(1-u^{-1}\right)-S\right)^{2}}{2 Q\left(1-u^{-1}\right)} I C-\frac{S^{2}}{2 Q\left(1-u^{-1}\right)} C_{2} .
\end{aligned}
$$

By differentiating Eq. (8) with respect to $S$ for the fixed $c_{b}$ and equating it to zero, we obtain the optimal value of $S$ :

$$
S=\frac{I C Q\left(1-u^{-1}\right)}{C_{2}+I C} .
$$

The profit function defined by Eq. (8) is concave in $S$, since:

$$
\frac{\partial^{2}}{\partial S^{2}} T P_{s}^{c}\left(c_{b}, S\right)=\frac{-I C+C_{2}}{\left(1-u^{-1}\right) Q}<0 .
$$

Upon substituting Eq. (9) into Eq. (8), we get

$$
\begin{gathered}
T P_{s}^{c}\left(c_{b}, S\right)=K p_{b}^{-e} M^{\beta}\left(c_{b}-C-\frac{A_{S}}{Q}\right) \\
-\frac{C_{2}^{2} Q\left(1-u^{-1}\right)}{2\left(C_{2}+I C\right)^{2}} I C-C_{2} \frac{Q\left(1-u^{-1}\right)(I C)^{2}}{2\left(C_{2}+I C\right)^{2}} .
\end{gathered}
$$

The profit function obtained from Eq. (11) is linearly increasing with $c_{b}$. In this regard, to obtain the optimal value of $c_{b}$, we set it to the highest price value negotiated between seller and buyer. We get:

$$
\begin{aligned}
c_{b}= & F c_{b_{0}}=F\left(\left(C+\frac{A_{S}}{Q}\right)\right. \\
& \left.+\frac{C_{2}^{2} Q\left(1-u^{-1}\right)}{2 d\left(C_{2}+I C\right)^{2}} I C+C_{2} \frac{Q\left(1-u^{-1}\right)(I C)^{2}}{2 d\left(C_{2}+I C\right)^{2}}\right)
\end{aligned}
$$

for some $F>1$.

\section{The non-cooperative Stackelberg games}

The Stackelberg game is a strategic game where the leader moves first and then, another player follows by making the best response. Two players, i.e., the seller and buyer, interact with one another. The objective of the dominant player is to maximize his gain on the basis of response by a follower.

\subsection{The Seller-Stackelberg model}

In the Seller-Stackelberg model, the seller is the leader, while the buyer is a follower. The seller makes his first move by offering values of his decision variables, i.e., the selling price $\left(c_{b}\right)$ and shortages $(S)$ to the buyer. Based on these values offered by the seller, the buyer, as a follower, determines the optimal value of his decision variables, i.e., the selling price $\left(p_{b}\right)$, marketing expenditure $(M)$, and order quantity $(Q)$ defined by Eqs. (4), Eq. (5), and Constraint (7), respectively. The seller's objective is to maximize his profit. Now, the problem can be mathematically described as:

$$
\begin{aligned}
\max & {\left[P_{s}^{c}\left(c_{b}, S\right)\right]=\left(c_{b} D-C D-\frac{A_{s}}{Q} D\right) } \\
& -I C A_{1}-C_{2} B_{1}=K p_{b}^{-e} M^{\beta}\left(c_{b}-C-\frac{A_{S}}{Q}\right) \\
& -\frac{\left(Q\left(1-u^{-1}\right)-S\right)^{2}}{2 Q\left(1-u^{-1}\right)} I C-\frac{S^{2}}{2 Q\left(1-u^{-1}\right)} C_{2} .
\end{aligned}
$$

Subject to:

$$
\begin{aligned}
& p_{b}= \frac{e}{(e-\beta-1)(1-E[\alpha])}\left[c_{b}+\frac{A_{b}}{Q}+\frac{I c_{b} E[\alpha] Q}{\lambda}\right. \\
&\left.-c_{s} E[\alpha]\right], \quad \beta+1<e, \\
& M= \frac{\beta}{(e-\beta-1)}\left[c_{b}+\frac{A_{b}}{Q}+\frac{I c_{b} E[\alpha] Q}{\lambda}-c_{s} E[\alpha]\right], \\
& \beta+1<e,
\end{aligned}
$$

and constraint:

$$
\begin{aligned}
2 D & \left(A_{b}-E[\alpha] I C_{b} \lambda^{-1} Q^{2}\right) \\
= & \left(\left(1-u^{-1}\right)^{2} Q^{2}-S^{2}\right) \frac{I C_{b}\left(E\left[(1-\alpha)^{2}\right]+(u-1)^{-1}\right)}{(1-E[\alpha])} \\
& -\left(\frac{C_{1} S^{2}}{\left(1-u^{-1}\right)(1-E[\alpha])}\right) .
\end{aligned}
$$

Cycle length, $T=\max \left(T_{1}, T_{2}\right)$.

Substituting Eqs. (14) and (15) into Eq. (13) as well as the resulting equation with a nonlinear constraint defined by Eq. (16) yield the optimum solution by any nonlinear programming search tool. 


\subsection{The Buyer-Stackelberg model}

In the Buyer-Stackelberg model, the initiative of giving the first offer to the buyer, the leader, is considered. The buyer makes his first move by offering the selling price $\left(p_{b}\right)$ marketing expenditure $(M)$ and order quantity $(Q)$ to the seller. Based on this offer, the seller determines the optimal value of his decision variables, i.e., shortages $(S)$ and selling price $\left(c_{b}\right)$, obtained from Eqs. (9) and (12). The buyer's objective is to optimize his profit. Here, the problem can be mathematically described as:

$$
\begin{aligned}
\max E[ & \left.T P_{b}^{c}\left(p_{b}, M, Q\right)\right]=E\left[T P_{b}^{c}\left(p_{b}, M, Q\right)\right] \\
= & k p_{b}^{-e+1} M^{\beta}+\frac{K p_{b}^{-e} M^{\beta}}{(1-E[\alpha])}\left[c_{s} E[\alpha]-c_{b}-M-\frac{A_{b}}{Q}\right. \\
& \left.-\frac{E[\alpha] Q}{\lambda} I c_{b}\right]-\frac{1}{2 Q(1-E[\alpha])}\left(\left(E\left[(1-\alpha)^{2}\right]\right.\right. \\
& \left.+(u-1)^{-1}\right) I c_{b}\left(Q\left(1-u^{-1}-S\right)^{2}\right) \\
& -C_{1} \frac{S^{2}}{2\left(1-u^{-1}\right)(1-E[\alpha])}
\end{aligned}
$$

Subject to:

$$
\begin{aligned}
S= & \frac{I C Q\left(1-u^{-1}\right)}{C_{2}+I C}, \\
c_{b}= & F c_{b_{0}}=F\left(\left(C+\frac{A_{S}}{Q}\right)\right. \\
& +\frac{C_{2}^{2} Q\left(1-u^{-1}\right)}{2 d\left(C_{2}+I C\right)^{2}} I C \\
& \left.+\frac{C_{2} Q\left(1-u^{-1}\right)(I C)^{2}}{2 d\left(C_{2}+I C\right)^{2}}\right)
\end{aligned}
$$

for some $F>1$.

Followed by substituting Eqs. (18) and (19) in Eq. (17), we can convert this problem into a non-constrained non-linear function of three variables $\left(p_{b}, M\right.$, and $\left.Q\right)$, which can be solved using any non-linear programming search tool.

\section{Numerical illustrations}

This section gives some numerical examples to elaborate on some specific features of the given model mentioned above. The first case of the numerical examples is based on the Seller-Stackelberg and BuyerStackelberg models. The second case makes the comparison between the results obtained from models with and without shortage $(S=0)$. This explanation reveals the effect of profits of buyer and seller.

\subsection{Numerical examples for non-cooperative game with shortages}

Example 1. This example shows the effect of the defective items in the Seller-Stackelberg game model. The input parameters used are derived from the studies conducted by Zhang et al. [53] and Jaggi et al. [38], as shown below:

$$
\begin{array}{llll}
C=\$ 1.5, & C_{1}=\$ 1, & C_{2}=\$ 1, & A_{b}=\$ 40, \\
A_{s}=\$ 140, & C_{s}=3.5, & I=0.1, & u=1.1, \\
k=3500, & F=1.25, & e=1.7, & \beta=0.15, \\
\lambda=175200 \text { units/year. } & &
\end{array}
$$

The percentage of the items of imperfect quality rate, $\alpha$, is taken as uniformly distributed on $(a, b), 0<a<$ $b<1$, i.e., $\alpha U(a, b)$. Assuming that $a=0$ and $b=0.04$, we get:

$$
\begin{aligned}
& E[\alpha]=\frac{a+b}{2}=0.02 \\
& E\left[(1-\alpha)^{2}\right]=\int_{a}^{b}(1-\alpha)^{2} f(\alpha) d \alpha \\
& \quad=\frac{a^{2}+a b+b^{2}}{3}+1-a-b=0.960 .
\end{aligned}
$$

Consideration of Eq. (13) with Eqs. (14) and (15) as well as the constraints defined by Eq. (16) will yield:

$$
\begin{array}{ll}
c_{b}=\$ 4.472, & S=29, \quad Q=639 \text { units, } \\
p_{b}=\$ 14.081, & M=\$ 1.218 .
\end{array}
$$

Through Eq. (12) through which the seller's profit can be obtained, we have $\left[T P_{s}^{c}\right]=\$ 102.32$. Eq. (1) is used to obtain the buyer's expected profit, hence $E\left[T P_{b}^{c}\right]=$ $\$ 322.256$.

Example 2. This example is given to show the effect of the defective items in the Buyer-Stackelberg model. The same input parameters are taken into account as those in Example 1, with the exception of $c_{s}=1.5$. Eq. (17) along with Eqs. (14) and (15) gives:

$$
\begin{aligned}
& p_{b}=\$ 6.158, \quad M=\$ 0.532, \quad Q=1436 \text { units, } \\
& c_{b}=\$ 2.056, \quad S=17 .
\end{aligned}
$$

Eq. (17) was used to determine the buyer's expected profit; then, $E\left[T P_{b}^{c}=\$ 502.033\right.$. In addition, Eq. (18) was employed to obtain the seller's profit so that $\left[T P_{s}^{c}\right]=\$ 57.864$.

Based on the examples, it can be concluded that when a buyer is the leader as in the Buyer-Stackelberg model, he is better off as he gains much more profit while the selling price, which is charged by the buyer to the customer, is lower. Shortages are fewer in 
the Buyer-Stackelberg model. Since the production capacity is linearly related to the demand and the buyer is better informed about the end demand, the order quantity will be accordingly adjusted. In the second example, higher order quantity yields better profit for the buyer. The first example shows that the seller's selling price is high due to which the profit for the seller is also high. It can be also concluded that both players are better off when they are leader.

\subsection{Numerical example for the models without shortage}

All parameters are considered to be the ones in the previous example. In this case, the results obtained from the two different models are compared (the models without shortage are denoted by $W S$ ). The numerical results were then analyzed to determine the effect of the decision variables and profit functions for both players, i.e., the buyer and seller, due to the shortages.

Example 3. The optimal values obtained from the Seller-Stackelberg game model in the $W S$ case are $Q^{W S}=281$ units, $c_{b}^{W S}=\$ 4.402, p_{b}^{W S}=\$ 14.11$, and $M^{W S}=\$ 1.22$. Based on these results, the seller's expected profit, $E\left[T P_{s}^{c}\right]=\$ 94.354$, and the buyer's expected profit, $E\left[T P_{b}^{c}\right]=\$ 326.838$, can be obtained.

A comparison of the results from two SellerStackelberg models without and with shortages was made here. The marketing expenditure and buyer's selling price in the model without shortage are greater than those in the model with shortage. In addition, the seller's price and order quantity in the $W S$ case are smaller than those in the shortage case. Seller's profit is larger in no shortage case than to with shortage case, while buyer's profit is more in $W S$ case. Apparently, in Seller-Stackelberg game where the seller enjoys the advantage of being a leader and manages the shortages very well, the shortages get a negative impact on the buyer's profit when the buyer being follower.

Example 4. The optimal values obtained in the Buyer-Stackelberg game model in the $W S$ case are $p_{b}^{W S}=\$ 6.179, M^{W S}=\$ 0.534, Q^{W S}=1368$ units, and $c_{b}^{W S}=\$ 2.068$. According to these results, the seller's and buyer's expected profits are $E\left[T P_{s}^{c}\right]=$ $\$ 57.710$ and $E\left[T P_{b}^{c}\right]=\$ 499.867$, respectively.

The comparison of the outcome with the result of the shortage case reveals that the buyer has a larger order quantity and a lower selling price in the shortage case compared to the $W S$ case, while the seller's price and marketing expenditure are lower in the shortage case than those in the $W S$ case. Both players, i.e., seller and buyer, gain more profits in the shortage case than in the $W S$ case. The presence of shortage induces the buyer to order more quantity to fulfill the demand avoiding profit loss, hence a win-win situation for both players.

\section{Sensitivity analysis}

To further analyze the impact of the following parameters $\alpha, \beta, e, C_{1}$, and $C_{2}$ on $c_{b}, p_{b}, M, S, Q$, $D, E\left[T P_{s}^{c}\right]$, and $E\left[T P_{b}^{c}\right]$ in both Seller-Stackelberg and Buyer-Stackelberg models, sensitivity analysis of effective parameters was carried out. The obtained results are shown in Figures 4-8.

Further, the sensitivity analysis is conducted to determine the impact of shortages, $S$, on $c_{b}, p_{b}, M$, $Q, E\left[T P_{s}^{c}\right]$, and $E\left[T P_{b}^{c}\right]$ in the Seller-Stackelberg and Buyer-Stackelberg games. The results are demonstrated in the bar diagrams (Figures 9 and 10), comparing the results obtained in both cases in both non-

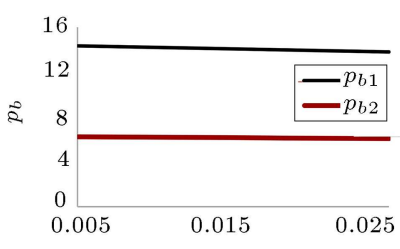

Fraction of defective items

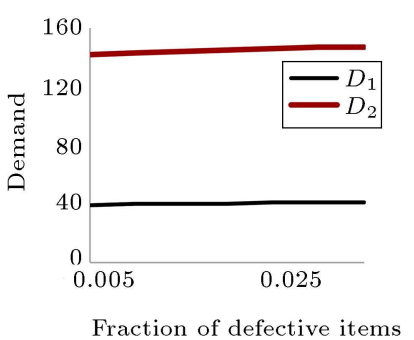

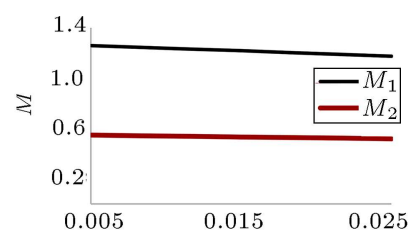

Fraction of defective items

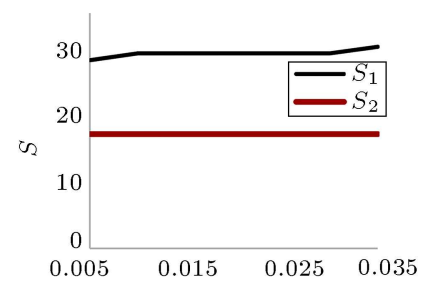

Fraction of defective items

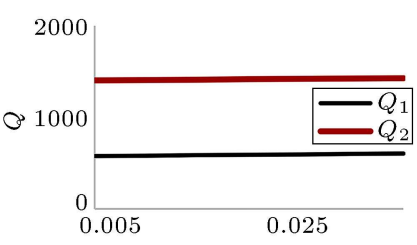

Fraction of defective items

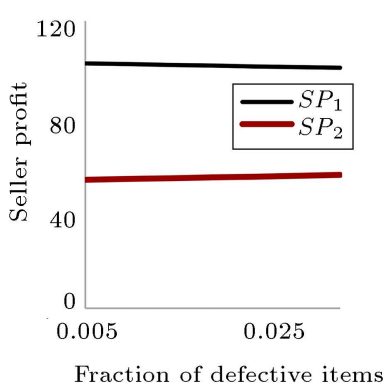

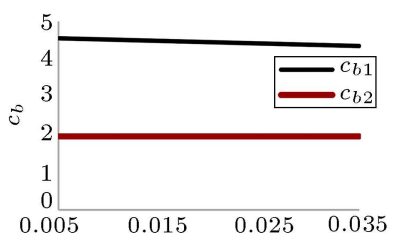

Fraction of defective items

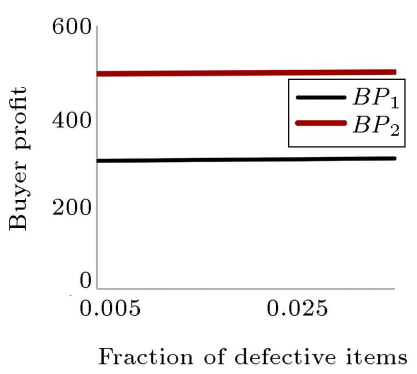

Figure 4. The effect of $\alpha$ parameter on $p_{b}, M, Q, c_{b}, S, D, E\left[T P_{s}^{c}\right]$, and $E\left[T P_{b}^{c}\right]$. 

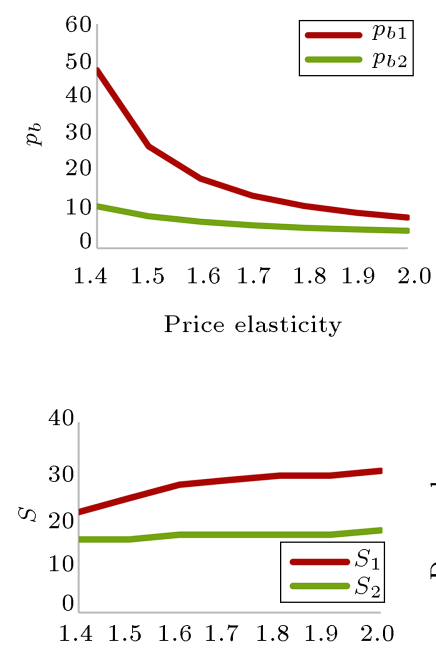

Price elasticity
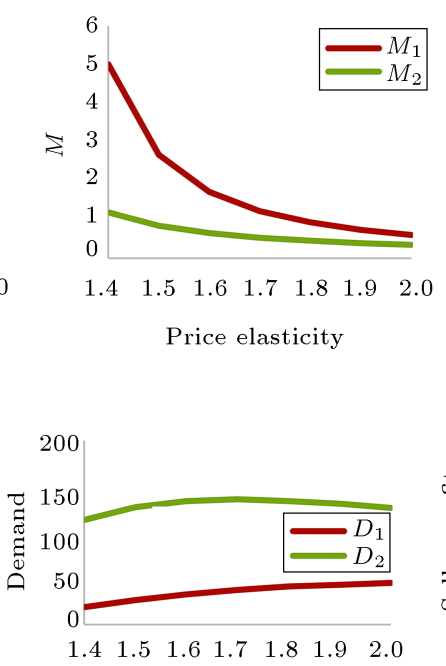

Price elasticity
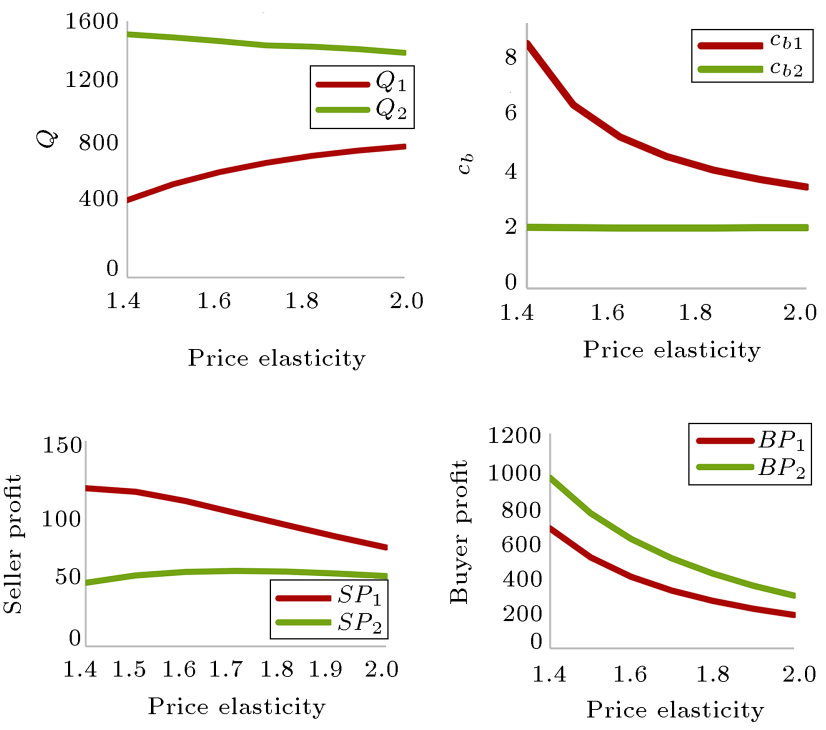

Figure 5. The effect of $e$ parameter on $p_{b}, M, Q, c_{b}, S, D, E\left[T P_{s}^{c}\right]$, and $E\left[T P_{b}^{c}\right]$.
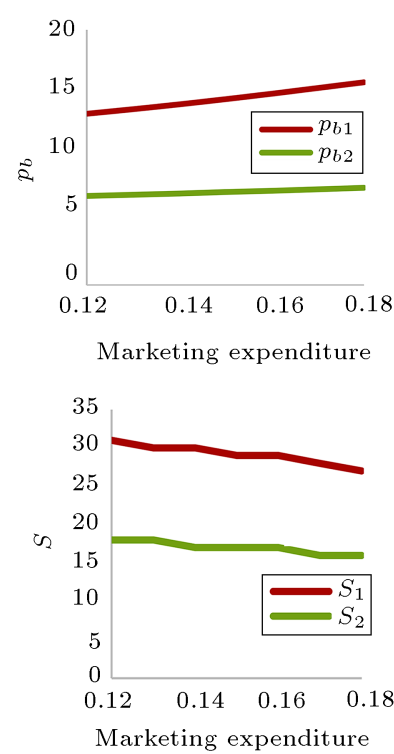
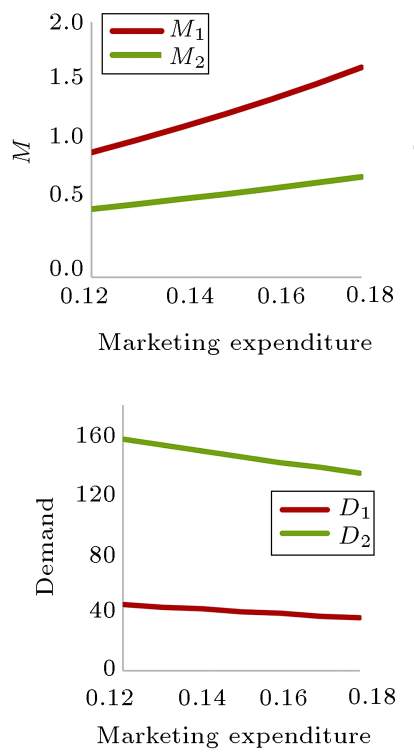
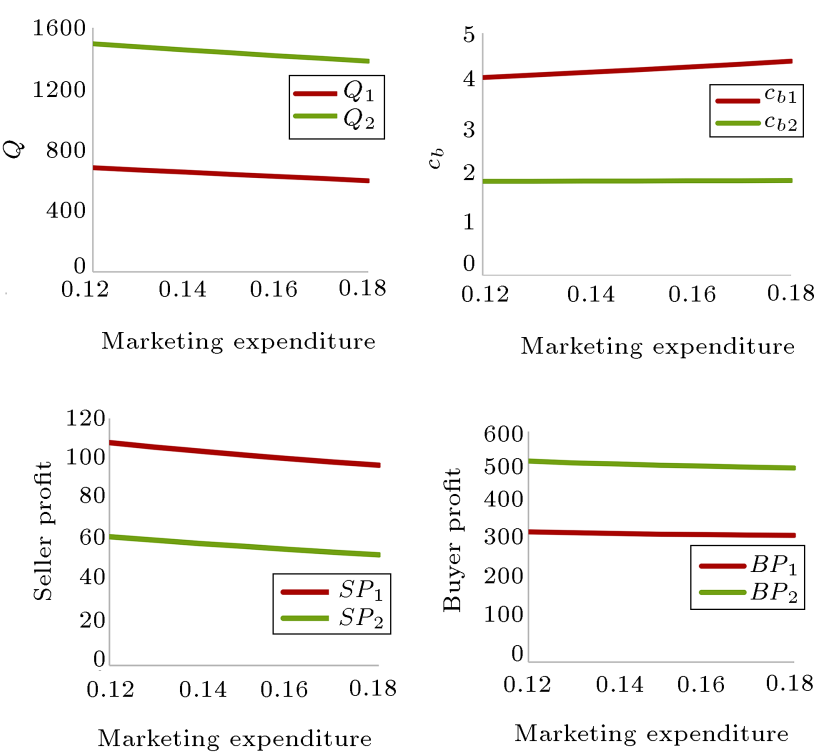

Figure 6. The effect of $\beta$ parameter on $p_{b}, M, Q, c_{b}, S, D, E\left[T P_{s}^{c}\right]$, and $E\left[T P_{b}^{c}\right]$.

cooperative games.

\section{Observations:}

1. Evidently, according to Figure 4, whenever the items of imperfect quantity increase in number, the variables $M, p_{b}$, and $Q$ that depend on the buyer's decision become independent of the buyer's leadership position. However, the seller's decision variables $S$ and $c_{b}$ are also absolute to the seller's position as a either follower or a leader. Both players benefit more when they are the leader than the case when they are follower;

2. From Figure 5 , it can be concluded that $S$ and $c_{b}$, the seller's decision variables, depend on whether the seller is a leader or a follower. For instance, $c_{b}$ decreases and $S$ increases in the Seller-Stackelberg model when increasing the value of price elasticity, $e$. In addition, $c_{b}$ increases and $S$ decreases in the Buyer-Stackelberg model. However, the buyer's leadership position affects $p_{b}$ and $Q$, while it has no effect on $M$. For example, increase in e causes $M$ to decrease, irrespective of the buyer's position $\left(p_{b}\right)$ and the value of $Q$ increases in the Seller-Stackeberg game, while it decreases in the Buyer-Stackelberg game. Being a leader is more beneficial for both of the players than to being a follower;

3. It can be easily seen from Figure 6 that in both models, as parameter $\beta$ increases, decision vari- 

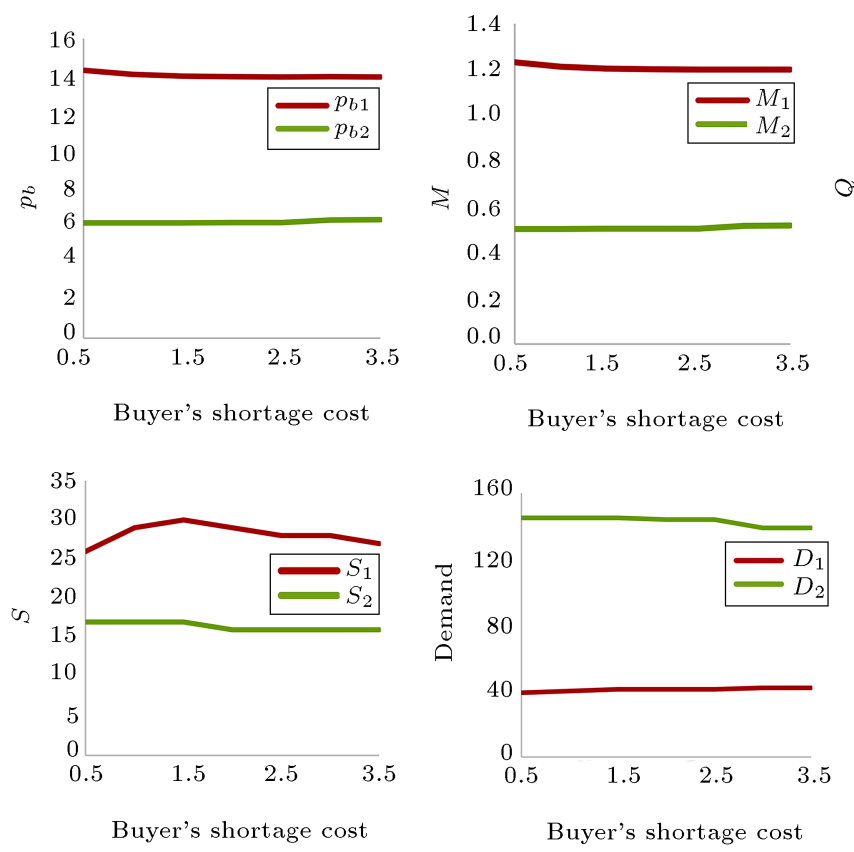
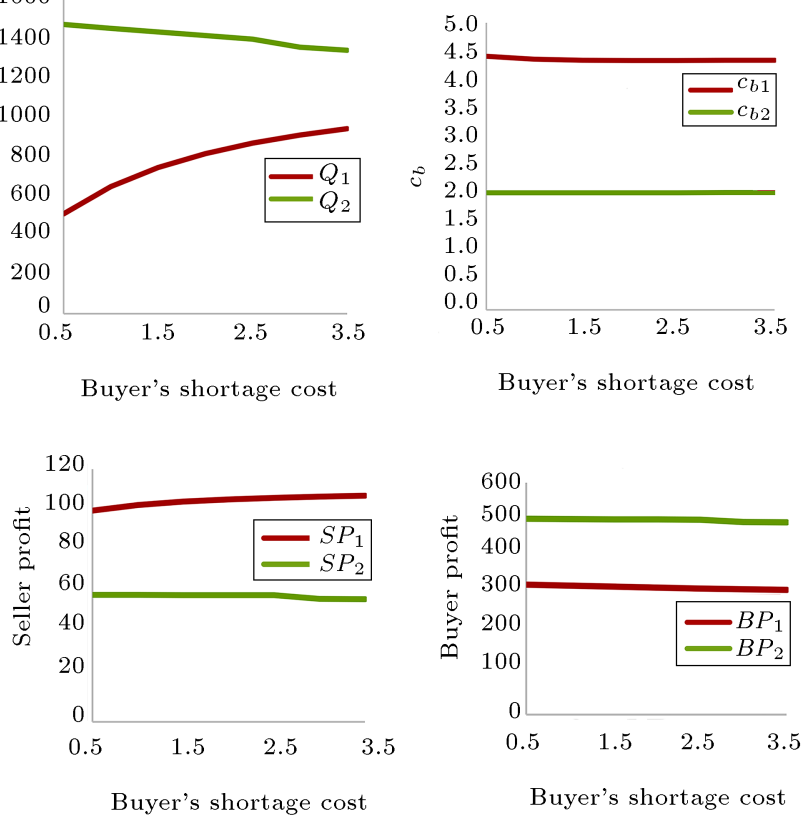

Figure 7. The effect of $C_{1}$ parameter on $p_{b}, M, Q, c_{b}, S, D, E\left[T P_{s}^{c}\right]$, and $E\left[T P_{b}^{c}\right]$.
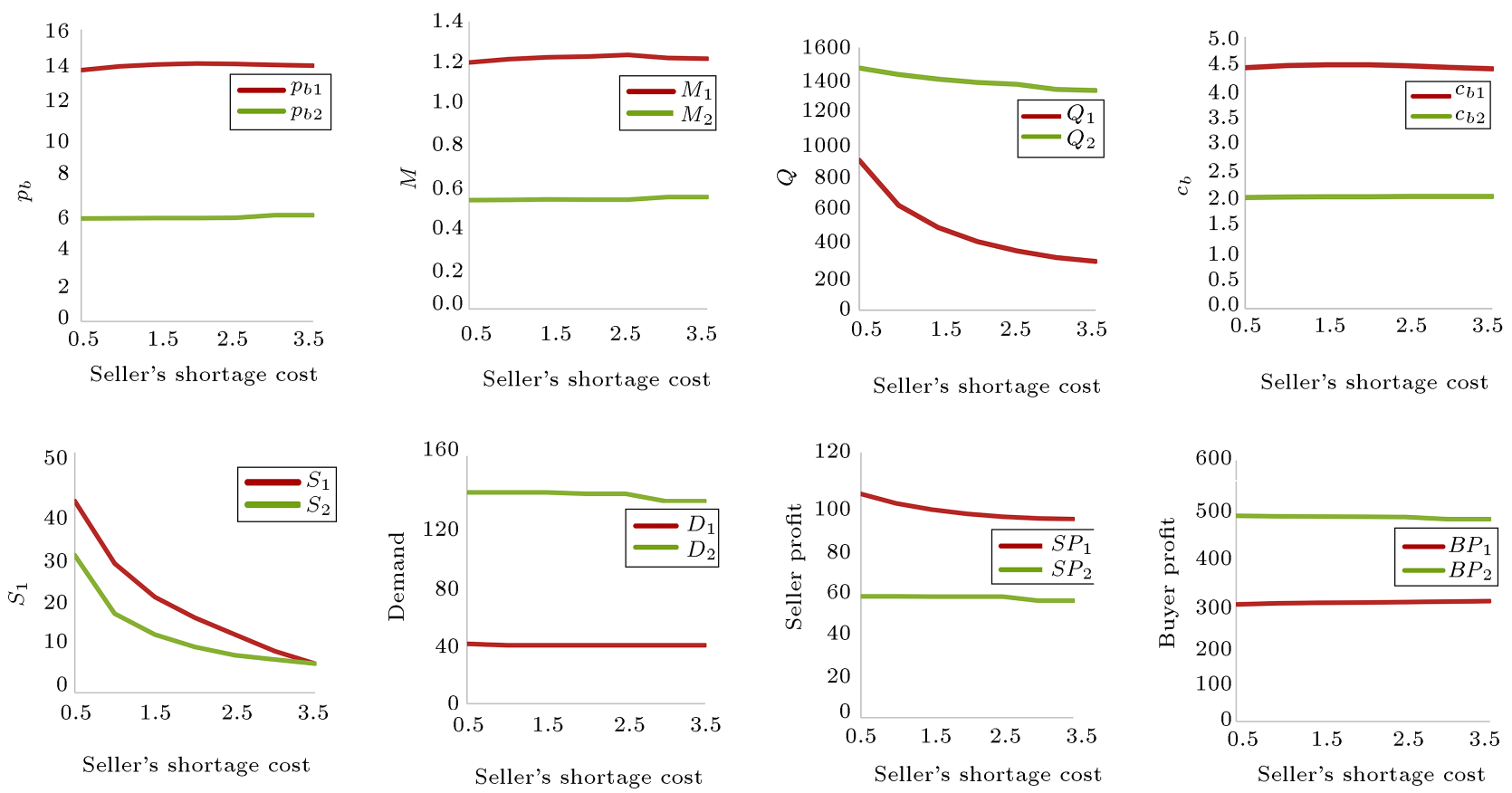

Figure 8. The effect of $C_{2}$ parameter on $p_{b}, M, Q, c_{b}, S, D, E\left[T P_{s}^{c}\right]$, and $E\left[T P_{b}^{c}\right]$.

ables, $c_{b}, p_{b}$, and $M$ increase, whereas $Q$ and $S$ are reduced, i.e., leadership situation does not affect the decision variables of the seller and buyer;

4. Results given in Figures 7 and 8 indicate that by varying $C_{1}$ and $C_{2}$, the profit of seller and buyer is heterogeneously affected in numerous ways for various models. For example, increasing $C_{1}$ in the non-cooperative game results in the reduction of the buyer's profit, whereas the seller's profit will increase. Both the decision variables of the seller increase before $C_{1}$ reaches $C_{2}$ and decreases when it exceeds $C_{2}$. The decision variables of the buyer $p_{b}$ and $M$ decrease and $Q$ increases as the buyer's shortage cost increases. In the Buyer-Stackelberg game, as $C_{1}$ increases, the shortage size $(S)$ and order quantity $(Q)$ are reduced, whereas $c_{b}, p_{b}$, and $M$ increase. 


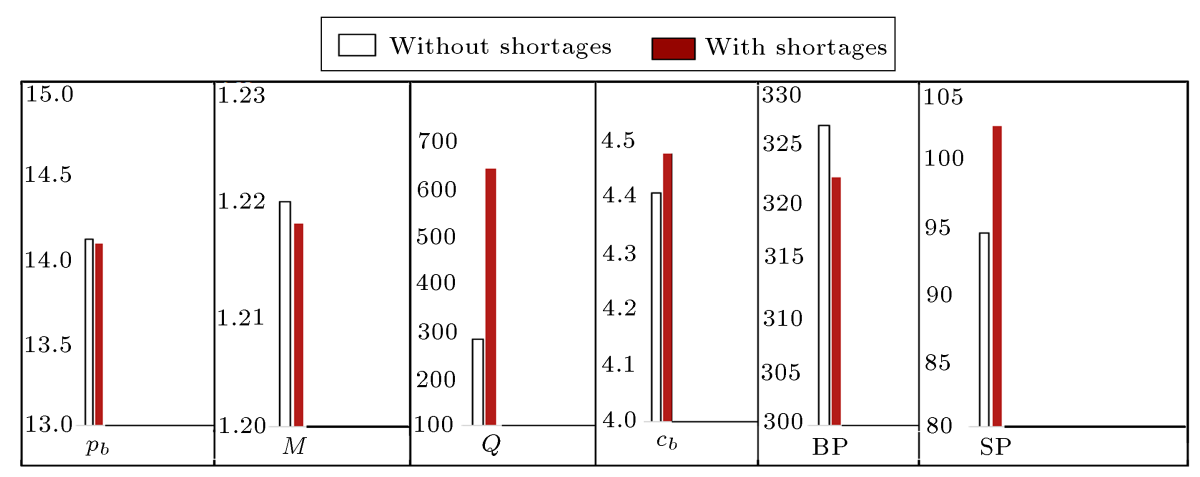

Figure 9. The Seller-Stackelberg game: Without shortages and with shortages.

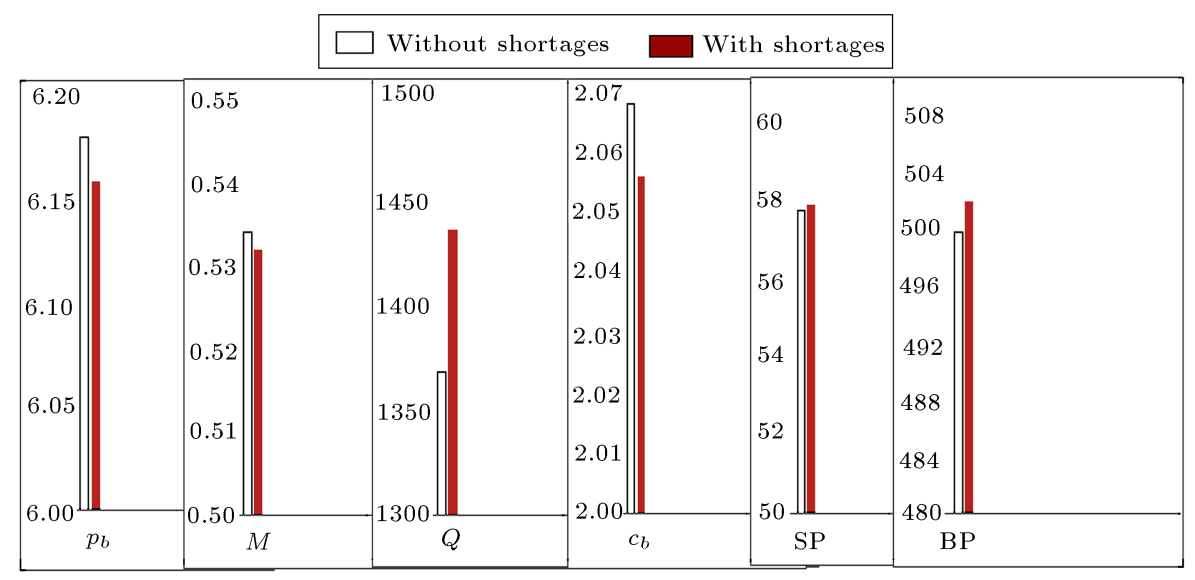

Figure 10. The Buyer-Stackelberg game: without shortages and with shortages.

\section{Conclusions}

The present study conducted a thorough examination of imperfect quality items under the supply chain model where shortages are permitted. The shortage is referred to as the seller's decision variable, which is related to the seller-buyer supply chain model, considering the effect of shortage under a symmetric information pattern on the performance and decision of the supply chain participants. The demand was assumed to be a function of the buyer's selling price and marketing expenditure. The interaction among the members was also investigated in a non-cooperative situation using the Stackelberg equilibrium, and the advantages and disadvantages were discussed in the case of Stackelberg games. The seller and buyer always gained more profit only when the two players were both leaders. The effect of shortage on the member's profit was reviewed with numerous examples. The graphs depicted the results obtained from the sensitivity analysis.

The results indicate that the costs, i.e., $C_{1}$ (buyer's shortages cost) and $C_{2}$ (seller's shortages cost) pertaining to the shortage, affect the seller and buyer profits in many ways for both models. For example, an increase in the value of $C_{1}$ in the non-cooperative game decreases the buyer's profit and increases the seller's profit. Both the decision variables of the seller increase before $C_{1}$ reaches $C_{2}$ and decrease when $C_{1}$ exceeds $C_{2}$. Further, we can extend the model by incorporating the asymmetric information structure.

\section{References}

1. Jüttner, U., Christopher, M., and Baker, S. "Demand chain management-integrating marketing and supply chain management", Ind. Mark. Manag., 36(3), pp. 377-392 (2007).

2. Chen, M.S., Chang, H.J., Huang, C.W., et al. "Channel coordination and transaction cost: A gametheoretic analysis", Ind. Mark. Manag., 35(2), pp. 178-190 (2006).

3. Yang, S.L., and Zhou, Y.W. "Two-echelon supply chain models: Considering duopolistic retailers' different competitive behaviors", Int. J. Prod. Econ., 103(1), pp. 104-116 (2006).

4. Dai, Y., Chao, X., Fang, S.C., and Nuttle, H.L. "Pricing in revenue management for multiple firms competing for customers", Int. J. Prod. Econ., 98(1), pp. 1-16 (2005).

5. Chiang, W.C., Fitzsimmons, J., Huang, Z., et al. "A game-theoretic approach to quantity discount problems", Deci. Sci., 25(1), pp. 153-168 (1994). 
6. Sarmah, S.P., Acharya, D., and Goyal, S.K. "Buyer vendor coordination models in supply chain management", Eur. J. Oper. Res., 175(1), pp. 1-15 (2006).

7. Weng, Z.K. "Channel coordination and quantity discounts", Manag. Sci., 41(9), pp. 1509-1522 (2007).

8. Shekarian, E. "A review of factors affecting closed-loop supply chain models", J. Clean. Prod., 253, p. 119823 (2020).

9. Chan, C.K. and Kingsman, B.G. "Coordination in a single-vendor multi-buyer supply chain by synchronizing delivery and production cycles", Transp. Res. E: Log. Transp. Rev., 43(2), pp. 90-111 (2007).

10. Dai, T. and Qi, X. "An acquisition policy for a multisupplier system with a finite-time horizon", Comput. Oper. Res., 34(9), pp. 2758-2773 (2007).

11. Van den Heuvel, W., Borm, P., and Hamers, H. "Economic lot-sizing games", Eur. J. Oper. Res., 176(2), pp. 1117-1130 (2007).

12. Sucky, E. "Inventory management in supply chains: A bargaining problem", Int. J. Prod. Econ., 93, pp. 253262 (2005).

13. Sucky, E. "A bargaining model with asymmetric information for a single supplier-single buyer problem", Eur. J. Oper. Res., 171(2), pp. 516-535 (2006).

14. Gautam, P. and Khanna, A. "An imperfect production inventory model with setup cost reduction and carbon emission for an integrated supply chain", Uncertain Supply Chain Manag., 6(3), pp. 271-286 (2018).

15. Lee, W.J. "Determining order quantity and selling price by geometric programming: optimal solution, bounds, and sensitivity", Decis. Sci., 24(1), pp. 7687 (1993).

16. Abad, P.L. "Supplier pricing and lot sizing when demand is price sensitive", Eur. J. Oper. Res., 78(3), pp. 334-354 (1994).

17. Kim, D. and Lee, W.J. "Optimal coordination strategies for production and marketing decisions", Oper. Res. Lett., 22(1), pp. 41-47 (1998).

18. Jung, H. and Klein, C.M. "Optimal inventory policies for an economic order quantity model with decreasing cost functions", Eur. J. Oper. Res., 165(1), pp. 108$126(2005)$.

19. Abad, P.L. and Jaggi, C.K. "A joint approach for setting unit price and the length of the credit period for a seller when end demand is price sensitive", Int. J. Prod. Econ., 83(2), pp. 115-122 (2003).

20. Sadjadi, S.J., Oroujee, M., and Aryanezhad, M.B. "Optimal production and marketing planning", Comput. Optim. Appl., 30(2), pp. 195-203 (2005).

21. Lee, W.J. and Kim, D. "Optimal and heuristic decision strategies for integrated production and marketing planning", Decis. Sci, 24(6), pp. 1203-1214 (1993).

22. Esmaeili, M., Aryanezhad, M.B., and Zeephongsekul, P. "A game theory approach in seller-buyer supply chain", Eur. J. Oper. Res., 195(2), pp. 442-448 (2009).
23. Esmaeili, M. and Zeephongsekul, P. "Seller-buyer models of supply chain management with an asymmetric information structure", Int. J. Prod. Econ., 123(1), pp. 146-154 (2010).

24. Silbermayr, L. "A review of non-cooperative newsvendor games with horizontal inventory interactions", Omega, 92, p. 102148 (2020).

25. Schwaller, R.L. "EOQ under inspection costs", Prod. Inventory Manag. J., 29(3), p. 22 (1988).

26. Rosenblatt, M.J. and Lee, H.L. "Economic production cycles with imperfect production processes", IIE Trans., 18(1), pp. 48-55 (1986).

27. Salameh, M.K. and Jaber, M.Y. "Economic production quantity model for items with imperfect quality", Int. J. Prod. Econ., 64(1-3), pp. 59-64 (2000).

28. Maddah, B. and Jaber, M.Y. "Economic order quantity for items with imperfect quality: revisited", Int. J. Prod. Econ., 112(2), pp. 808-815 (2008).

29. Ross, S.M., Stochastic Processes, Second Edn., Wiley, New York (1996).

30. Wee, H.M., Yu, J., and Chen, M.C. "Optimal inventory model for items with imperfect quality and shortage backordering", Omega, 35(1), pp. 7-11 (2007).

31. Eroglu, A. and Ozdemir, G. "An economic order quantity model with defective items and shortages", Int. J. Prod. Econ., 106(2), pp. 544-549 (2007).

32. Sarkar, B. "An EOQ model with delay in payments and stock dependent demand in the presence of imperfect production", App. Math. Comput., 218(17), pp. 82958308 (2012).

33. Sarkar, B. and Moon, I. "An EPQ model with inflation in an imperfect production system", App. Math. Comput., 217(13), pp. 6159-6167 (2011).

34. Roy, M.D., Sana, S.S., and Chaudhuri, K. "An economic order quantity model of imperfect quality items with partial backlogging", Int. J. Sys. Sci., 42(8), pp. 1409-1419 (2011).

35. Cheikhrouhou, N., Sarkar, B., Ganguly, B., et al. "Optimization of sample size and order size in an inventory model with quality inspection and return of defective items", Ann. Oper. Res., 271, pp. 445-467 (2018).

36. Sarkar, B., Cárdenas-Barrón, L.E., Sarkar, M., et al. "An economic production quantity model with random defective rate, rework process and backorders for a single stage production system", J. Manuf. Syst., 33(3), pp. 423-435 (2014).

37. Tiwari, S., Cárdenas-Barrón, L.E., Khanna, A., et al. "Impact of trade credit and inflation on retailer's ordering policies for non-instantaneous deteriorating items in a two-warehouse environment", Int. J. Prod. Econ., 176, pp. 154-169 (2016).

38. Jaggi, C.K., Goel, S.K., and Mittal, M. "Credit financing in economic ordering policies for defective items with allowable shortages", App. Math. Comput., $\mathbf{2 1 9}(10)$, pp. 5268-5282 (2013). 
39. Khanna, A., Mittal, M., Gautam, P., et al. "Credit financing for deteriorating imperfect quality items with allowable shortages", Decis. Sci. Lett., 5(1), pp. 45-60 (2016).

40. Khanna, A., Gautam, P., and Jaggi, C.K. "Coordinating vendor-buyer decisions for imperfect quality items considering trade credit and fully backlogged shortages", AIP Conf. Proc., 1715(1), p. 020065 (2016).

41. Kishore, A., Gautam, P., Khanna, A., et al. "Investigating the effect of learning in set-up cost for imperfect production systems by utilizing two-way inspection plan for rework under screening constraints", Sci. Iran., 27(6), pp. 3265-3288 (2019).

42. Khanna, A., Gautam, P., Sarkar, B., et al. "Integrated vendor-buyer strategies for imperfect production systems with maintenance and warranty policy", RAIROOper. Res., 54(2), pp. 435-450 (2020).

43. Jaggi, C.K., Cárdenas-Barrón, L.E., Tiwari, S., et al. "Two-warehouse inventory model for deteriorating items with imperfect quality under the conditions of permissible delay in payments", Sci. Iran., 24(1), pp. 390-412 (2017).

44. Mittal, M., Khanna, A., and Jaggi, C.K. "Retailer's ordering policy for deteriorating imperfect quality items when demand and price are time-dependent under inflationary conditions and permissible delay in payments", Int. J. Process. Manag., 10(4), pp. 461494 (2017).

45. Esmaeili, M. "A new approach in determining lot size in supply chain using game theory", In Intelligent Mathematics II: Applied Mathematics and Approximation Theory, Springer Int. Pub., pp. 215-231 (2016).

46. Yadav, R., Pareek, S., and Mittal, M. "Supply chain model for imperfect quality items with trade credit financing: a game theoretical approach", Rev. Inve. Ope., 39(2), pp. 265-277 (2018).

47. Sarkar, B., Saren, S., Sarkar, M., et al. "A Stackelberg game approach in an integrated inventory model with carbon-emission and setup cost reduction", Sustainability, 8(12), p. 1244 (2016).

48. Lu, C.J., Yang, C.T., and Yen, H.F. "Stackelberg game approach for sustainable production-inventory model with collaborative investment in technology for reducing carbon emissions", J. Clean. Prod., 270, p. 121963 (2020).

49. Alaei, S. and Setak, M. "Supply chain coordination via a two-way cooperative advertising contract considering competing retailers", Sci. Iran., 23(5), pp. 23-30 (2016).

50. Jaggi, C.K., Gupta, M., Kausar, A., et al. "Inventory and credit decisions for deteriorating items with displayed stock dependent demand in two-echelon supply chain using Stackelberg and Nash equilibrium solution", Ann. Oper. Res., 274, pp. 309-329 (2019).

51. Yadav, R., Pareek, S., and Mittal, M. "Supply chain models with imperfect quality items when end demand is sensitive to price and marketing expenditure.", RAIRO-Oper. Res., 52(3), pp. 725-742 (2018).

52. Gautam, P., Kishore, A., Khanna, A., et al. "Strategic defect management for a sustainable green supply chain", J. Clean. Prod., 233, pp. 226-241 (2019).

53. Zhang, X., Zeephongsekul, P., and Esmaeili, M. "Seller-buyer supply chain games where shortage are permitted", J. Manag. Strat., 3(4), pp. 1-14 (2012).

54. Zhang, X. and Zeephongsekul, P. "Asymmetric supply chain models implementable with a mechanism design", App. Math. Model., 40(23-24), pp. 10719-10739 (2016).

55. Johnson, L.A. and Montgomery D.C. "Production planning-dynamic models", In Operations Research in Production Planning, Scheduling, and Inventory Control, pp. 187-297, John Wiley \& Sons, Inc. New York (1974)

56. Sadigh, A.N., Karimi, B., and Farahani, R.Z. "A game theoretic approach for two echelon supply chains with continuous depletion", Int. J. Manag. Sci. Eng. Manag., 6(6), pp. 408-412 (2011).

\section{Appendix A}

It is necessary to demonstrate that the expected profit function $E\left[T P_{b}^{c}\left(p_{b}, M, Q\right)\right]$ is strictly pseudo concave with respect to $p_{b}$ for fixed $M$ and $Q$ (Yadav et al. [46]). For this, we will show that for $p_{b 1} \neq p_{b 2}$, we have:

$$
\begin{aligned}
& E\left[T P_{b}^{c}\left(p_{b 1}, M, Q\right)\right] \leq E\left[T P_{b}^{c}\left(p_{b 2}, M, Q\right)\right] \\
& \quad=>\nabla\left(E\left[T P_{b}^{c}\left(p_{b 1}, M, Q\right)\right]\right)\left(p_{b 2}-p_{b 1}\right)>0 .
\end{aligned}
$$

The expected profit of the buyer from Eq. (1) is as follows:

$$
\begin{aligned}
& E\left[T_{b}^{c}\left(p_{b}, M, Q\right)\right]=p_{b} D+\frac{1}{(1-E[\alpha])}\left[c_{s} E[\alpha] D\right. \\
& -c_{b} D-M D-\frac{A_{b} D}{Q}-\left(\frac{E[\alpha] Q D}{\lambda}\right) I c_{b} \\
& -\frac{1}{2 Q}\left(\left(E\left[(1-\alpha)^{2}\right]+(u-1)^{-1}\right) I c_{b}\left(Q\left(1-u^{-1}-S\right)^{2}\right)\right. \\
& \left.-C_{1} \frac{S^{2}}{2\left(1-u^{-1}\right)}\right]=D\left(p_{b}+\frac{1}{(1-E[\alpha])}\left[c_{s} E[\alpha]\right.\right. \\
& \left.\left.-c_{b}-M-\frac{A_{b}}{Q}-\left(\frac{E[\alpha] Q}{\lambda}\right) I c_{b}\right]\right) \\
& -\frac{1}{2 Q}\left(\left(E\left[(1-\alpha)^{2}\right]+(u-1)^{-1}\right) I c_{b}\left(Q\left(1-u^{-1}-S\right)^{2}\right)\right. \\
& -C_{1} \frac{S^{2}}{2\left(1-u^{-1}\right)} .
\end{aligned}
$$


Suppose that the inequality is $E\left[T P_{b}^{c}\left(p_{b 1}, M, Q\right)\right] \leq$ $E\left[T P_{b}^{c}\left(p_{b 2}, M, Q\right)\right]$, which is equivalent to:

$$
\begin{gathered}
D_{2}\left[\frac{1}{(1-E[\alpha])}\left(c_{b}+M+\frac{A_{b}}{Q}+\frac{E[\alpha] Q}{\lambda} I c_{b}-c_{s} E[\alpha]\right)\right. \\
\left.\quad-p_{b 2}\right] \leq D_{1}\left[\frac { 1 } { ( 1 - E [ \alpha ] ) } \left(c_{b}+M+\frac{A_{b}}{Q}\right.\right. \\
\left.\left.+\frac{E[\alpha] Q}{\lambda} I c_{b}-c_{s} E[\alpha]\right)-p_{b 1}\right],
\end{gathered}
$$

where $D_{i}=D\left(p_{b i}, M\right)=k p_{b i}^{-e} M^{\beta}, i=1,2$.

To show the strictly pseudo concavity of expected profit function $E\left[T P_{b}^{c}\left(p_{b}, M, Q\right)\right]$ with respect to $p_{b}$ for fixed $M$ and $Q$, it should be proven that Inequality (A.1):

$$
=>\nabla\left(E\left[T P_{b}^{c}\left(p_{b 1}, M, Q\right)\right]\right)\left(p_{b 2}-p_{b 1}\right)>0 .
$$

Here, we have:

$$
\begin{gathered}
\nabla\left(E\left[T P_{b}^{c}\left(p_{b 1}, M\right)\right]\right)=D_{1}(1-e) p_{b 1}+\frac{D_{1} e}{(1-E[\alpha])} \\
\left(c_{b}+M+\frac{A_{b}}{Q}+\frac{E[\alpha] Q}{\lambda} I c_{b}-c_{s} E[\alpha]\right) .
\end{gathered}
$$

Putting the value of Eq. (A.3) in Eq. (A.2), we will have:

$$
\begin{gathered}
\left(D_{1}(e-1) p_{b 1}-\frac{D_{1} e}{(1-E[\alpha])}\left(c_{b}+M+\frac{A_{b}}{Q}\right.\right. \\
\left.\left.+\frac{E[\alpha] Q}{\lambda} I c_{b}-c_{s} E[\alpha]\right)\right)\left(p_{b 2}-p_{b 1}\right)<0 .
\end{gathered}
$$

To show the strictly pseudo concavity of the expected profit function $E\left[T P_{b}^{c}\left(p_{b}, M\right)\right]$ with respect to $p_{b}$ for fixed $M$ and $Q$, it is sufficient to show that Eq. (A.1) implies:

$$
\begin{gathered}
\left(D_{1}(e-1) p_{b 1}-\frac{D_{1} e}{(1-E[\alpha])}\left(c_{b}+M+\frac{A_{b}}{Q}\right.\right. \\
\left.\left.+\frac{E[\alpha] Q}{\lambda} I c_{b}-c_{s} E[\alpha]\right)\right)\left(p_{b 2}-p_{b 1}\right)<0
\end{gathered}
$$

Let:

$$
P=\frac{1}{(1-E[\alpha])}\left(c_{b}+M+\frac{A_{b}}{Q}+\frac{E[\alpha] Q}{\lambda} I c_{b}-c_{s} E[\alpha]\right) .
$$

Then, Eq. (A.1) can be rewritten as:

$$
D_{2}\left(P-p_{b 2}\right) \leq D_{1}\left(P-p_{b 1}\right),
$$

and Eq. (A.4) can be rewritten as:

$$
D_{1}\left((e-1) p_{b 1}-e P\right)\left(p_{b 2}-p_{b 1}\right)<0,
$$

i.e.:

$$
p_{b 2}\left((e-1) p_{b 1}-e P\right)<p_{b 1}\left((e-1) p_{b 1}-e P\right) .
$$

Suppose that there are two distinct points, $p_{b 2}$ and $p_{b 1}$. Then, either (a) $p_{b 2}>p_{b 1}$ or (b) $p_{b 2}<p_{b 1}$ (Sadigh et al. [56]).

Case (a): Let $p_{b 2}>p_{b 1}$ that follows $D_{1}>D_{2}$. Therefore, to prove Eq. (A.5), it suffices to show that:

$$
\frac{D_{2}}{D_{1}}\left(P-p_{b 2}\right) \leq\left(P-p_{b 1}\right)
$$

Since $p_{b 2}>p_{b 1}$, we have $\left(P-p_{b 2}\right)<\left(P-p_{b 1}\right)$. There are three possible cases for Eq. (A.6) which are as follows:

(i) $P-p_{b 1}>0$ and $P-p_{b 2}>0$,

(ii) $P-p_{b 1}>0$ and $P-p_{b 2}<0$,

(iii) $P-p_{b 1}<0$ and $P-p_{b 2}<0$.

Case (i): $P-p_{b 1}>0$ and $P-p_{b 2}>0$

$$
=>P-p_{b 1}>P-p_{b 2}=>p_{b 2}>p_{b 1}
$$

and:

$$
\frac{D_{2}}{D_{1}}<1 \Rightarrow \text { verified Eq. (A.6). }
$$

Here, $P-p_{b 1}>0=>P>p_{b 1}$. Since $0<(e-$ 1) $<e \Rightarrow(e-1) p_{b 1}<e p_{b 1}<e P \Rightarrow(e-1) p_{b 1}-e P<$ 0 . Hence, Eq. (A.5) holds.

If $P-p_{b 1}<P-p_{b 2} \Rightarrow p_{b 2}<p_{b 1}$, then it contradicts Eq. (A.6).

Case (ii): $P-p_{b 1}>0$ and $P-p_{b 2}<0$

$$
=>p_{b 2}>P \text { and } p_{b 1}<P \Rightarrow p_{b 2}>p_{b 1} \text {. }
$$

In this case, Eq. (A.6) holds since $-p_{b 1}>0$.

Case (iii): $P-p_{b 1}<0$ and $P-p_{b 2}<0$ :

$$
\begin{aligned}
& =>D_{2}\left(P-p_{b 2}\right) \leq D_{1}\left(P-p_{b 1}\right) \\
& =>p_{b 2}^{-e}\left(P-p_{b 2}\right) \leq p_{b 1}^{-e}\left(P-p_{b 1}\right) \\
& =>\left(\frac{p_{b 1}}{p_{b 2}}\right)^{e}\left(P-p_{b 2}\right) \leq\left(P-p_{b 1}\right) \\
& =>p_{b 1}^{e}\left(P-p_{b 2}\right) \leq p_{b 2}^{e}\left(P-p_{b 1}\right) \\
& =>P\left(p_{b 2}^{e}-p_{b 1}^{e}\right) \geq p_{b 1} p_{b 2}\left(p_{b 2}^{e-1}-p_{b 1}^{e-1}\right) \\
& =>P \geq \frac{p_{b 1} p_{b 2}\left(p_{b 2}^{e-1}-p_{b 1}^{e-1}\right)}{\left(p_{b 2}^{e}-p_{b 1}^{e}\right)} .
\end{aligned}
$$


Now, Eq. (A.7) shows that at a minimum value of:

$$
P=\frac{p_{b 1} p_{b 2}\left(p_{b 2}^{e-1}-p_{b 1}^{e-1}\right)}{\left(p_{b 2}{ }^{e}-p_{b 1}{ }^{e}\right)} \text {. }
$$

Eq. (A.6) holds. For this, we have:

$$
\begin{aligned}
& (e-1) p_{b 1}-e P=(e-1) p_{b 1} \\
& -e \frac{p_{b 1} p_{b 2}\left(p_{b 2}^{e-1}-p_{b 1}^{e-1}\right)}{\left(p_{b 2}{ }^{e}-p_{b 1}{ }^{e}\right)}<0 \\
& =>\frac{(e-1)}{e}<\frac{p_{b 2}\left(p_{b 2}^{e-1}-p_{b 1}^{e-1}\right)}{\left(p_{b 2}^{e}-p_{b 1}{ }^{e}\right)} \\
& =>\frac{(e-1)}{e}<\left(\frac{1-\left(\frac{p_{b 1}}{p_{b 2}}\right)^{e-1}}{1-\left(\frac{p_{b 1}}{p_{b 2}}\right)^{e}}\right) \\
& =>\left(\frac{p_{b 1}}{p_{b 2}}\right)^{e-1}\left[e+(1-e)\left(\frac{p_{b 1}}{p_{b 2}}\right)\right]<1 .
\end{aligned}
$$

Therefore, for each $e>1$ and $\left(\frac{p_{b 1}}{p_{b 2}}\right)<1$, Eq. (A.8) holds. Hence, the proof is completed for this case.

Case (b): Let $p_{b 2}<p_{b 1}$ that follows $D_{2}>D_{1}$ and it is sufficient to show that:

$$
\frac{D_{2}}{D_{1}}\left(P-p_{b 2}\right) \leq\left(P-p_{b 1}\right) \text {. }
$$

In a similar manner as mentioned in Case (a), three cases can be considered according to Eq. (A.9):

(i) $P-p_{b 1}>0$ and $P-p_{b 2}>0$,

(ii) $P-p_{b 1}>0$ and $P-p_{b 2}<0$,

(iii) $P-p_{b 1}<0$ and $P-p_{b 2}<0$.

Case (i): $P-p_{b 1}>0$ and $P-p_{b 2}>0$; this implies that $P-p_{b 1}>P-p_{b 2}=>p_{b 1}<p_{b 2}$ contradicts Eq. (A.9);

Case (ii): $P-p_{b 1}>0$ and $-p_{b 2}<0$

$$
=>p_{b 2}>P \text { and } p_{b 1}<P=>p_{b 1}<p_{b 2},
$$

contradicts Eq. (A.9);

Case (iii): $P-p_{b 1}<0$ and $P-p_{b 2}<0$ :

$$
\begin{aligned}
& =>D_{2}\left(P-p_{b 2}\right) \leq D_{1}\left(P-p_{b 1}\right) \\
& =>p_{b 2}^{-e}\left(P-p_{b 2}\right) \leq p_{b 1}^{-e}\left(P-p_{b 1}\right) \\
& =>\left(\frac{p_{b 1}}{p_{b 2}}\right)^{e}\left(p_{b 2}-P\right) \geq\left(p_{b 1}-P\right) \\
& =>p_{b 1}^{e}\left(p_{b 2}-P\right) \geq p_{b 2}^{e}\left(p_{b 1}-P\right) \\
& =>P\left(p_{b 1}^{e}-p_{b 2}^{e}\right) \leq p_{b 1} p_{b 2}\left(p_{b 1}^{e-1}-p_{b 2}^{e-1}\right) \\
& =>P \leq \frac{p_{b 1} p_{b 2}\left(p_{b 1}^{e-1}-p_{b 2}^{e-1}\right)}{\left(p_{b 1}{ }^{e}-p_{b 2}{ }^{e}\right)} .
\end{aligned}
$$

Similar to Eq. (A.7), Eq. (A.10) can be proved at the maximum value of:

$$
P=\frac{p_{b 1} p_{b 2}\left(p_{b 1}^{e-1}-p_{b 2}^{e-1}\right)}{\left(p_{b 1}{ }^{e}-p_{b 2}{ }^{e}\right)},
$$

for each, $e>1$ and $\left(\frac{p_{b 1}}{p_{b 2}}\right)>1$. Here, the proof is completed for $p_{b 2}<p_{b 1}$.

Hence, Eq. (A.5) holds in all possible cases. Thus the expected profit of the buyer is strictly pseudo concave with respect to $p_{b}$ for fixed $M$ and $Q$.

\section{Appendix B}

In this part, it is demonstrated that the expected profit function $E\left[T P_{b}^{c}\left(p_{b}(M), M, Q\right)\right]$ is concave with respect to $M$ for fixed $Q$ :

$$
\begin{aligned}
& E\left[T P_{b}^{c}\left(p_{b}(M), M, Q\right)\right]=\frac{K}{e}\left[p_{b}\right]^{-e+1} M^{\beta} \\
& -\frac{1}{2 Q}\left(( E [ ( 1 - \alpha ) ^ { 2 } ] + ( u - 1 ) ^ { - 1 } ) I c _ { b } \left(Q \left(1-u^{-1}\right.\right.\right. \\
& \left.-S)^{2}\right)-C_{1} \frac{S^{2}}{2\left(1-u^{-1}\right)}
\end{aligned}
$$

Through Eq. (2), we have:

$$
\begin{aligned}
& p_{b}=\frac{e}{(e-1)(1-E[\alpha])}\left[M+c_{b}+\frac{A_{b}}{Q}\right. \\
& \left.\quad+\frac{I c_{b} E[\alpha] Q}{\lambda}-c_{s} E[\alpha]\right], \\
& \frac{\partial p_{b}}{\partial M}=\frac{e}{(e-1((1-E[\alpha])}, \\
& \frac{\partial E\left[T P_{b}^{c}\left(p_{b}(M), M, Q\right)\right]}{\partial M}=D\left[-\frac{1}{(1-E[\alpha])}+\frac{p_{b} \beta}{e M}\right], \\
& \frac{\partial^{2} E\left[T P_{b}^{c}\left(p_{b}(M), M, Q\right)\right]}{\partial M^{2}}=D\left[-\frac{p_{b}(M) \beta}{e M^{2}}\right. \\
& \left.\quad+\frac{\beta}{M(e-1)(1-E[\alpha])}\right]+D\left[-\frac{1}{(1-E[\alpha])}\right. \\
& \left.\quad+\frac{p_{b}(M) \beta}{e M}\right]\left[\frac{\beta}{M}-\frac{e}{p_{b}(M)}\right] .
\end{aligned}
$$

Through Eqs. (4) and (5), we have:

$$
p_{b}=\frac{e M}{\beta(1-E[\alpha])} .
$$

Putting the value of Eq. (B.2) in Eq. (B.1), we have: 


$$
\frac{\partial^{2} E\left[T P_{b}^{c}\left(p_{b}(M), M, Q\right)\right]}{\partial M^{2}}=\frac{D(\beta+1-e)}{M(1-E[\alpha])(e-1)}<0,
$$

by assumption, $\beta+1<e, e>1$. This shows the concavity of the expected profit with respect to $M$ for fixed $Q$.

\section{Biographies}

Rita Yadav has served as an Associate Professor at the Department of Mathematics at Dronacharya College of Engineering, Gurgaon for fourteen years. She was a gold medalist of the year 1998 in Pure Mathematics at MSc from Banasthali Vidyapith, Rajasthan, India. Further, she received $\mathrm{PhD}$ degree in Game Theory in the year 2019 from Banasthali Vidyapith, Rajasthan. She authored two books on engineering mathematics. Her research interest includes game theory and supply chain management. She has published various research papers in international/national journals including, YUJOR, USCM, RAIRO Operations Research, springer, and EEE proceedings.

Sarla Pareek is a Professor in Statistics. She has 32 years of teaching experience. Currently, she is the Dean of the Faculty of Mathematics and Computing at Banasthali Vidyapith. She is a life member of various academic bodies and has published more than 50 research articles in various reputed journals. She has also guided $12 \mathrm{MPhil}$ and $20 \mathrm{PhD}$ students. She completed two government-funded projects. Her area of research includes inventory models, demography, and applied statistics.

Mandeep Mittal began his career in the education industry in 2000 with Amity Group. Currently, he is working as the Head of an Associate Professor at the Department of Mathematics, Amity Institute of Applied Sciences, Amity University Uttar Pradesh, Noida. He earned his post-doctorate from Hanyang University, South Korea in 2016, PhD (2012) from the University of Delhi, India, and postgraduation in Applied Mathematics from IIT Roorkee, India (2000). He has published more than 70 research articles in international journals and conferences. He has authored one book with Narosa Publication on $\mathrm{C}$ language and edited five research books with IGI Global and Springer. He is a series editor of Inventory Optimization, Springer Singapore Pvt. Ltd. He has been awarded Best Faculty Award by the Amity School of Engineering and Technology, New Delhi for the year 2016-2017. He guided 4 PhD scholars and 5 students working with him in the area of inventory control and management. He also served as the Dean of Students Activities at Amity School of Engineering and Technology, Delhi for nine years and worked as the Head of the Department of Mathematics at the same institute for a year. He is a member of the editorial boards of Revista Investigation Operational, Journal of Control and Systems Engineering, and Journal of Advances in Management Sciences and Information Systems. He actively participates as a core member of organizing committees in international conferences in and outside India. 